\title{
Kazdağ Masifi’nde (Biga Yarımadası) Yer Alan Meta-Ofiyolitik Kayaların TitaniQ Termometresi ve Rutil İz Element Bileşimi
}

\author{
TitaniQ Thermometer and Trace Element Composition of Rutile in Meta-Ophiolitic Rocks From \\ the Kazdăg Massif, Biga Peninsula
}

\section{Firat ŞENGÜN}

Çanakkale Onsekiz Mart Üniversitesi, Mühendislik Fakültesi, Jeoloji Mühendisliği Bölümü, 17100, Çanakkale, Türkiye (e-posta: firatsengun@comu.edu.tr)

\section{öz}

Ofiyolitik meta-gabrolar Biga Yarımadası'nın güneyinde Kazdă̆ Masifi'nde yüzlek vermektedir. Metagabrolar içerisindeki rutil ve kuvars minerallerinin iz element bileşimleri LA-ICP-MS ile saptanmıştır. Hem matriks içerisinde hem de granat içerisinde kapanım olarak bulunan rutil tanelerinin Zr içeriği 176 ile 428 ppm arasında değişmekte ve ortalama Zr içeriği ise 335 ppmdir. Rutil taneleri genellikle homojen Zr dağılımına sahiptir. Kazdă̆ Masifi'nde incelenen örnekler içerisindeki rutil taneleri subkondritik $\mathrm{Nb} / \mathrm{Ta}$ (11-23) ve $\mathrm{Zr} / \mathrm{Hf}$ (20-33) değerleriyle karakterize olmaktadır. $\mathrm{Nb} / \mathrm{Ta}$ ve $\mathrm{Zr} / \mathrm{Hf}$ pozitif korelasyon göstermekte ve bu da muhtemelen silikat parçalanmasından kaynaklanmaktadır. $\mathrm{Nb} / \mathrm{Ta}$ ve $\mathrm{Zr} / \mathrm{Hf}$ oranları Ta ve Hf içeriklerindeki azalmayla artma eğilimi sunmaktadır. Rutil tanelerinin çekirdekleri genellikle düşük $\mathrm{Nb} / \mathrm{Ta}$ (17-18) oranlarıyla karakterize olurken kenar kesimleri göreceli olarak daha yüksek $\mathrm{Nb} /$ Ta (19-23) oranlarına sahiptir. Rutilin iz element analizleri rutil kristallerinin metamorfik akışkanlardan itibaren geliştiğini göstermektedir.

Kuvarsın Ti içeriği rutilin Zr içeriğine göre geliştirilen termometreyle birlikte kullanıldığında kuvars ve rutilin birlikte bulunduğu kayalarda basınç-sıcaklık hesabı yapılabilmektedir. Ofiyolitik meta-gabroların basınç-sıcaklık koşulları kuvarsın Ti içeriğine ve rutilin Zr içeriğine göre hesaplanmıştır. Kuvarsın Ti içeriği 28 ile 42 ppm arasında değişmekte ve ortalama 36 ppmdir. Basınç-sıcaklık diyagramında kuvarsın Ti eş değer eğrileri ile rutilin $\mathrm{Zr}$ eş değer eğrileri çakıştırıldığında elde edilen sıcaklık değeri $\sim 660{ }^{\circ} \mathrm{C}$, basınç değeri ise $~ 10$ kbardır. Meta-ofiyolitik kayaların basınç-sıcaklık koşulları bu kayaların Kazdağ Masifi içerisinde daha yüksek basınçlı ayrı bir tektonik dilim olduğunu ifade etmektedir. Amfibolit fasiyesi metamorfizması Neo-Tetis okyanusunun İzmir-Ankara kolunun kuzeye doğru Sakarya Zonu altına dalmasından kaynaklanmaktadır. Metamorfizmanın hemen ardından Kazdă̆ Masifi'nin ortayüksek dereceli metamorfik kayaları kendi içerisinde çarpışma sırasında güneye doğru sıkışmayla birbiri üzerine bindirmiştir.

Anahtar Kelimeler: Metamorfizma, Rutil, Kuvars, Termobarometre, Meta-gabro 


\section{ABSTRACT}

Ophiolitic meta-gabbros are exposed on the Kazdăg Massif located in the southern part of the Biga Peninsula. Trace element composition of rutile and quartz was determined for metagabbros from the Kazdağ Massif by LA-ICP-MS. The Zr content of both matrix rutiles and rutile inclusions in garnet range from 176 to 428 ppm (average 335 ppm). Rutile grains usually have a homogeneous Zr distribution. The rutile grains from studied samples in the Kazdağ Massif are dominated by subchondritic Nb/Ta (11-23) and $\mathrm{Zr} / \mathrm{Hf}$ ratios (20-33). $\mathrm{Nb} / \mathrm{Ta}$ and $\mathrm{Zr} / \mathrm{Hf}$ show positive correlation, which is probably produced by silicate fractionation. The $\mathrm{Nb} / \mathrm{Ta}$ and $\mathrm{Zr} / \mathrm{Hf}$ ratios increase with a decrease in Ta and $\mathrm{Hf}$ contents. The core of rutile grains are generally characterized by low Nb/Ta ratios of 17-18 whereas the rims exhibit relatively high $\mathrm{Nb}$ /Ta ratios of 19-23. Trace element analyses in rutile suggest that these rutile grains were grown from metamorphic fluids.

Ti-in-quartz can be used as a thermobarometer when used in combination with Zr-in-rutile thermometer. $P-T$ conditions of ophiolitic meta-gabbros were calculated by Ti content of quartz and Zr content of rutile, which are in equilibrium with each other. Ti contents of quartz are ranging between 28 and 42 ppm (average $36 \mathrm{ppm}$ ). A P-T estimate can be obtained from the intersection of the Ti-in-quartz isopleths with the Zr-in-rutile isopleths, which yield $\sim 660^{\circ} \mathrm{C}$ and $10 \mathrm{kbar}$. The P-T conditions of meta-ophiolitic rocks suggest that they occur as a different separate higher-pressure tectonic slice in the Kazdağ Massif. Amphibolite-facies metamorphism resulted from northward subduction of the İmir-Ankara branch of the Neo-Tethyan Ocean under the Sakarya Zone. Metamorphism was followed by internal imbrication of the Kazdăg Massif resulting from southerly directed compression during the collision.

Key words: Metamorphism, Rutile, Quartz, Thermobarometer, Meta-gabbro

\section{GíRiș}

Kuvarsin $\left(\mathrm{SiO}_{2}\right)$ magmatik, metamorfik, hidrotermal ve sedimanter kayalarda yaygın olarak bulunması, kuvarsın geniş bir basınçsıcaklık (P-T) aralığında duraylı kalabildiğini göstermektedir. Kuvarsın iz element jeokimyası kayaların kristalleşme koşulları hakkında önemli bilgiler vermektedir. Kuvarsin ve rutilin $\left(\mathrm{TiO}_{2}\right)$ birlikte kristalizasyonu sırasında titanyumun (Ti) kuvarsın silisyumu (Si) ile yer değiştirmesi basınç ve sıcaklığa bağlıdır ve bu da tek mineralli kuvarsın Ti içeriğine bağl1 TitaniQ termometresinin gelişmesine neden olmuştur (Wark ve Watson, 2006; Thomas vd. 2010). Kuvarsın Ti içeriğinin basınç ve sıcaklılığa bağımlılığı, kuvarsla birlikte gelişen başka bir mineral termometresiyle (rutilin $\mathrm{Zr}$ içeriğine bağlı termometre) birleştirildiğinde termobarometre olarak ya da bağımsız olarak kuvars kristalizasyonunun basınç ve sıcaklığının hesaplanmasında kullanılabilmektedir (Thomas vd. 2010, 2015). Benzer şekilde kuvars ve zirkonla birlikte dengede olan rutilin kristal kafesine sıcaklığa bağımlı zirkonyumun (Zr) dahil olması tek mineralli termometrenin (rutilin $\mathrm{Zr}$ içeriğine bağlı termometre) gelişmesini sağlamıştır (Zack vd. 2004; Watson vd. 2006; Ferry ve Watson, 2007; Tomkins vd. 2007). TitaniQ ve rutil termometreleri tek mineralli termometreler olup yaygın olarak orta-yüksek dereceli metamorfik kayaların metamorfizma sıcaklıklarının ve basınçlarının sınırlandırılmasında kullanılmaktadır (örn. Spear vd. 2006; Zhang vd. 2009; Meyer vd. 2011; Ewing vd. 2013; Gao vd. 2014). 
Rutil aksesuar mineral olarak okyanusal ve kıtasal yitim zonlarındaki orta-yüksek dereceli metamorfik kayalarda yaygin olarakbulunmakta ve basınç-sıcaklık koşullarıyla ilişkili ana metamorfik reaksiyonlara katılmaktadır (örn. Foley vd. 2002; Zack vd. 2002; Meinhold, 2010; Ding vd. 2013). Rutil yüksek alan gücüne sahip elementleri taşıan başlıca titanyum içeren faz olup yitim zonu sistemlerindeki kayaların içerisinde yer alan Nb, Ta ve Ti'un büyük bölümünü kapsamaktadır (Brenan vd. 1994; Green, 1995; Foley vd. 2000; Rudnick vd. 2000; Ding vd. 2013). Rutil aynı zamanda yapısında geniş oranda $\mathrm{V}, \mathrm{Cr}, \mathrm{Fe}, \mathrm{Al}$, $\mathrm{Sn}, \mathrm{Sb}$ ve $\mathrm{W}$ gibi iz elementleri barındırmaktadır (örn. Graham ve Morris, 1973; Deer vd. 1992; Zack vd. 2002). Rutilin Nb/Ta oranlar1 yitim zonu metamorfizması boyunca kabuk-manto ayırımının jeokimyasal olarak izlenmesinde kullanılmaktadır (Schmidt vd. 2008; 2009; Meinhold, 2010).

Önceki çalışmalarda Kazdağ Masifi'nin metamorfik istifi gnays, amfibolit, mermer ve meta-ofiyolitik kayalardan oluşan metamorfik kompleks olarak tanımlanmıştır (Okay vd. 1996, 2006; Duru vd. 2004). Bununla birlikte metamorfik kayaların içyapısı, kontak ilişkileri ve kökenleri halen tartışma halindedir. Meta-ofiyolitlerin metamorfik evrimleri ve tektonik yerleşimleri ile ilgili problemler ise henüz çözülmemiştir.

$\mathrm{Bu}$ çalışmada TitaniQ termometresi meta-ofiyolitik kayaların basınç-sıcaklık koşullarının hesaplanması için meta-ofiyolitik kayaların içinde yayılım sunan meta-gabrolara uygulanmıştır. TitaniQ termometresi rutil ve zirkonla dengede bulunan kuvars mineralinin iz element konsantrasyonlarından elde edilen basınç-sıcaklık değerlerinin yitim zonu sistemleri için ne kadar güvenilir olduğunun belirlenebilmesi ve klasik yöntemlerle hesaplanan basınçsıcaklık değerleriyle karşılaştırılabilmesi için incelenmiştir. Ayrıca rutil jeokimyası ile yitime uğramış okyanusal kabuğun iz element davranışı ve yitim zonu süreçlerindeki metamorfik evrimi değerlendirilmiştir. Bu çalışmanın amacı ortayüksek dereceli metamorfik kayalardan elde edilen rutillerden yitime uğramış okyanusal kabuğun metamorfik evrimi ile ilgili önemli bilgiler sağlamak ve TitaniQ termometresiyle Kazdağ Masifi'nde yüzlek veren meta-ofiyolitik kayaların basınç-sıcaklık koşullarının hesaplanarak metamorfik evriminin ortaya çıkarılmasıdır.

\section{JEOLOJIKK YERLEŞİM}

Türkiye yaygın olarak Mesozoyik ve Senozoyik sirasinda Tetis okyanusal havzaların kapanan kollarını temsil eden ofiyolitik sütur zonlarıyla ayrılmış tektonik zonlardan oluşmaktadır (Şekil 1) (örn. Şengör ve Y1lmaz 1981; Okay ve Tüysüz 1999; Moix vd. 2008). Bunlar kuzeyden güneye doğru Sakarya Zonu (Okay, 1984), İzmir-Ankara Zonu (Şengör ve Yılmaz, 1981), Tavşanlı Zonu (Okay, 1986), Afyon Zonu (Okay, 1984), ve Menderes Masifidir (Dürr vd. 1978). 


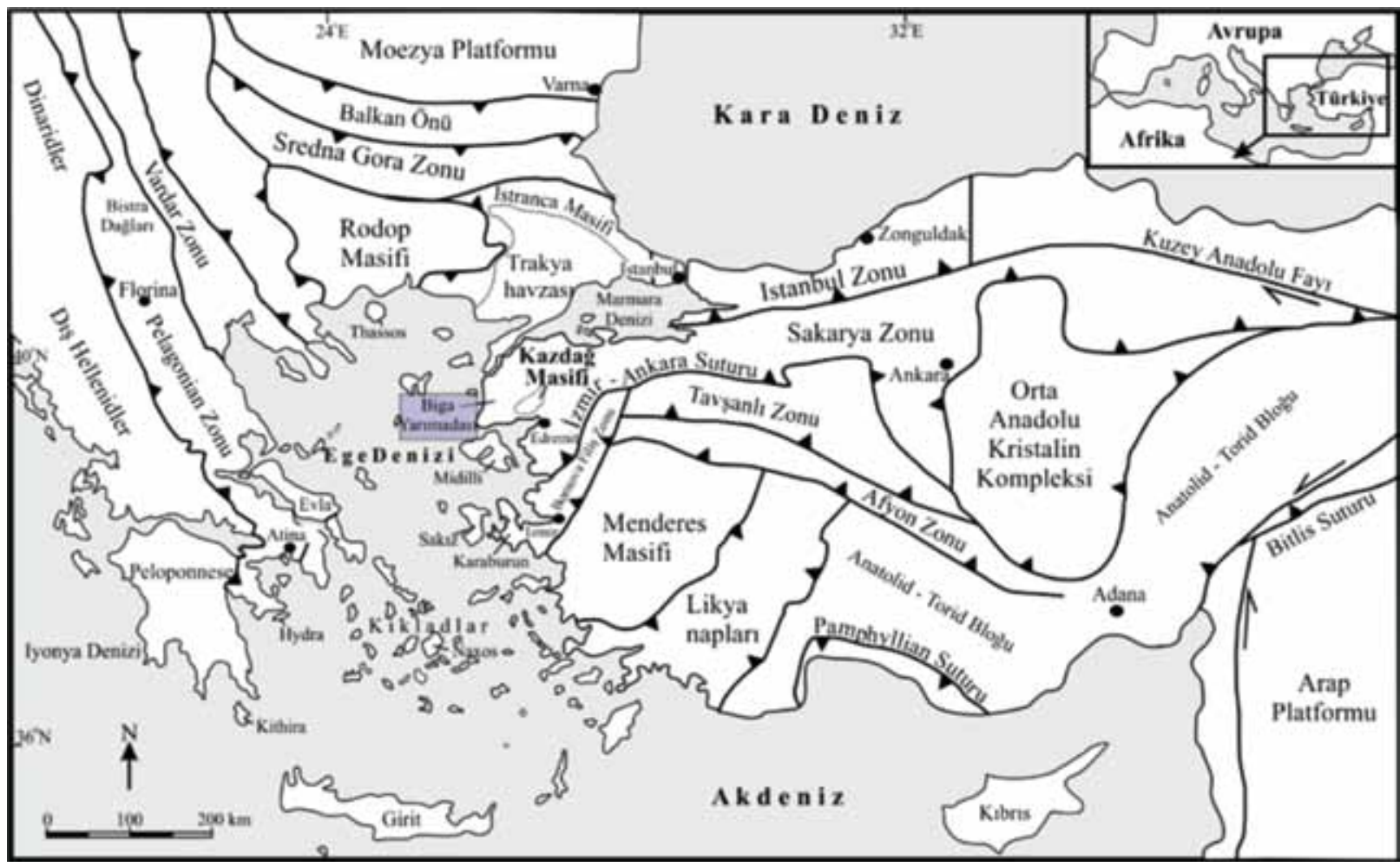

Şekil 1. Ana tektonik birimleri ve bunları sınırlayan süturları gösteren Doğu Akdeniz'in tektonik haritası (Okay vd. 2006; Meinhold vd. 2010'san değiştirilmiştir).

Figure 1. Tectonic map of the Eastern Mediterranean region indicating the major geotectonic units and the bounding sutures (modified from Okay et al. 2006; Meinhold et al. 2010).

Kuzeybatı Anadolu farklı tektonik birimlerin, farklı kökende ve yaşta kıtasal parçaların ve okyanusal topluluklarının bulunduğu bir bölgedir (Okay ve Satır, 2000; Beccaletto ve Jenny, 2004; Şengün vd. 2011; Aysal vd. 2012). Kazdağ MasifikuzeybatıAnadolu' da SakaryaZonu içerisinde Biga Yarımadası'nın güney kesiminde yer almaktadır (Şekil 2). Kazdağ Masifi KD-GB yönünde uzanan ve kuzeydoğu yönünde dalımlı bir antiform oluşturmaktadır. $\mathrm{Bu}$ antiformun çekirdeğindeki ileri derecede metamorfik temel kayaları tipik bir gnays domu görünümündedir. $\mathrm{Bu}$ ileri derecede metamorfik çekirdek, önce daha zayıf dereceli metamorfik bir Paleozoyik ve daha sonra da metamorfizma nitelikleri daha da düşük olan Erken Mesozoyik yaşlı birimler tarafından örtülür. Kazdağ Masifi üç tektonostratigrafik topluluktan oluşmaktadır (Şekil 3). Bunlar; i) Kazdağ Masifinin amfibolit-granulit fasiyesinde metamorfik çekirdeğini oluşturan; Kazdağ Grubu, ii) Yeşil şist fasiyesinde metamorfik, küçük metaofiyolit dilim ve mercekleri içeren ve Devoniyen yaşlı metagranitoyidlerle kesilen bir metavolkanik - metasedimenter istiften oluşan Kalabak Grubu, iii) İçerisinde yaygın Permiyen blokları da içeren çok geniş litolojik ve yapısal karaktere sahip Triyas yaşlı kalın volkanik - çökel düzenli ve karmaşık topluluk; Karakaya Grubu (Yiğitbaş vd. 2014). 


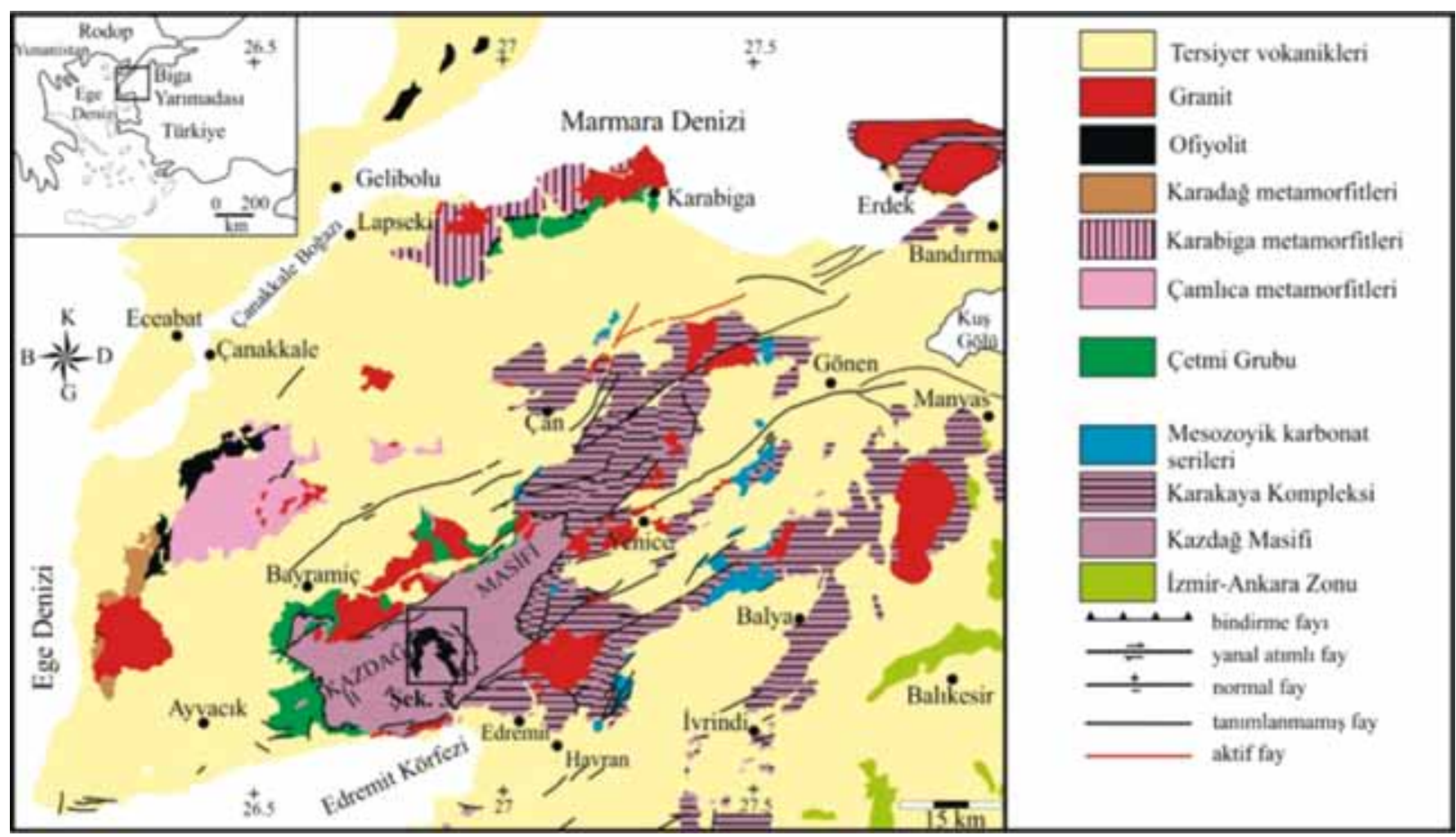

Şekil 2. Biga Yarımadası'nın genelleştirilmiş jeoloji haritası (MTA 2012'den değiştirilmiştir).

Figure 2. Generalized geological map of the Biga Peninsula (modified from MTA 2012).

Kazdağ Masifi'nde yüzlek veren metaofiyolitik kayalar antiformun çekirdeğinde bulunmakta ve mermerce zengin bir istif tarafindan çevrelenmektedir. Mermerce zengin istif üste doğru felsik gnays, migmatit, mermer ve amfibolit ardalanmasına geçmektedir (Bingöl, 1969; Picket ve Robertson, 1996; Okay ve Satır, 2000; Duru vd. 2004; Erdoğan vd. 2013). Tipik bir okyanusal kabuğu temsil eden meta-ofiyolitik kayalar meta- ultramafik kayalardan, koyu yeşil renkli, bantlı meta-gabrolardan oluşmaktadır (Şekil 3). Metaultramafik kayalar baskın olarak masif metapiroksenitlerden ve kısmen serpantinitleşmiş meta-dünitlerden oluşmaktadır. Meta-gabrolar genel olarak foliasyonlu ve ilksel dokusu yaygin bir şekilde korunmuştur. Bu birim mermer-gnays istifi tarafindan tektonik olarak üzerlenmektedir (Duru vd. 2004; Yiğitbaş vd. 2014). 


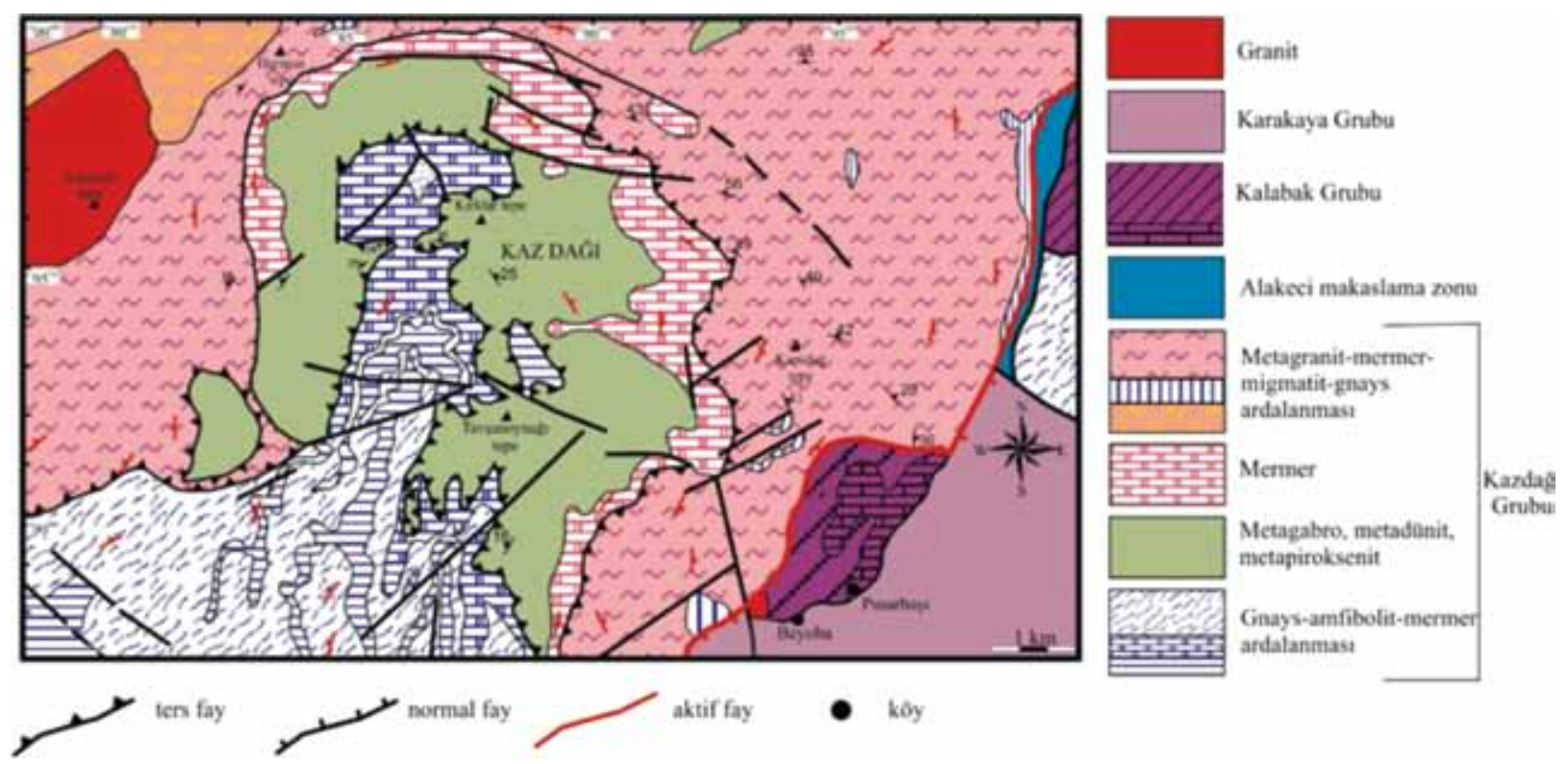

Şekil 3. Kazdağ Masifi'nde yüzlek veren meta-ofiyolitik kayaların ayrıntılı jeoloji haritası (Duru vd. 2004'den değiştirilmiştir).

Figure 3. Detailed geological map of the meta-ophiolitic rocks in the Kazdă̆ Massif (modified from Duru et al. 2004).

Kazdă̆ Masifi'nin metamorfik kayaları Alpin orojenezi sırasında sıkışma rejimi altında amfibolit-granulit fasiyesi metamorfizmasina uğramıştır ve metamorfik kayalara granitlerin yerleşmesi eşlik etmiştir (Okay ve Satır, 2000; Erdoğan vd. 2013). Kazdağ Masifi'ndeki felsik gnayslardan ve amfibolitlerden tek zirkon $\mathrm{Pb}$ evaporasyon metoduyla elde edilen yaşlar sırasıyla $308 \pm 16$ My ve $329 \pm 5$ My vermiştir (Okay ve Satır, 2000). Bununla birlikte Alpin üzerlemesini ile ilgili olarak Kazdağ Masifi'ndeki iki gnays örneğinden K-Ar mika yaşları $26 \pm 3$ My ve $27 \pm 3$ My vermiştir (Bingöl, 1969). Okay ve Satır (2000) gnays örneklerinden sirasıyla elde edilen $\mathrm{Rb} / \mathrm{Sr}$ muskovit ve biyotit yaşlarının 24-20 My ve 20-18 My toplandığını ifade etmişlerdir. Yakın zamanda metagranit örneklerinden elde edilen U-Pb zirkon yaşları $24.8 \pm 4.6$ My ve $28 \pm 10$ My olarak saptanmıştır. $\mathrm{Bu}$ yaşlar Alpin orojenezi sırasında Kazdağ Masifi'nde meydana gelen migmatitik metamorfizmanın yaşı olarak yorumlanmıştır (Erdoğan vd. 2013). Bu izotopik veriler Kazdağ Masifi'ndeki orta dereceli metamorfizmanın Karbonifer ve Geç Oligosen sırasında olduğunu göstermektedir (Okay vd. 1996; Okay ve Satır, 2000, Erdoğan vd. 2013; Yiğitbaş vd. 2014). Kazdağ Masifi'nin batı kenarında bulunan Alakeçi milonit zonundan 17-14 My arasında değişen apatit iz yaşları elde edilmiştir. Bu yaşlar Kazdağ Masifi'nin yüzeylemesiyle bağlantılıdır (Cavazza vd. 2009). Kazdağ Masifi litoloji ve metamorfizma zamanı bakımından Yunanistan'da bulunan Rodop Masifi ile karşılaştırılmıştır (örn. Beccaletto ve Jenny, 2004; Okay vd. 1996; Okay ve Satır, 2000)

Kazdağ Masifi'nin orta dereceli metamorfik kayaları Permo-Triyasik Karakaya Kompleksi tarafindan tektonik olarak üzerlenmektedir. Karakaya Kompleksi Paleotetis okyanusunun kapanmasını işaret eden düşük 
dereceli metamorfik kayalardan, sedimanter kayalardan, yığışım kompleksi, okyanus için yay/ yay önü birimlerden oluşmaktadır (Okay vd. 1996; Okay ve Göncüoğlu, 2004). Bununla birlikte sedimanter kayalar ve okyanus adası bazalt tipli volkanik bloklar düşük basınç-düşük sicaklık koşullarından etkilenmiştir (Tetiker vd. 2015).

\section{PETROGRAFI}

Meta-ofiyolitik kayalar içerisinde baskın litolojiyi oluşturan meta-gabrolar rutil, zirkon ve kuvars mineralleri içermektedir. Meta-gabroların ana mineral bileşimi plajioklas $(\sim 40 \%)$, hornblend ( $30 \%)$, klinopiroksen $(\sim 15 \%)$, ortopiroksen $(\sim$ $5 \%$ ) ve biyotitten $(\sim 5)$ oluşmaktadır. Aksesuar mineralleri olarak granat, epidot, klorit, $\mathrm{Ca}-$ amfibol, kuvars, rutil, titanit, zirkon, apatit ve ilmenit içermektedir (Şekil 4). Bütün metagabro örnekleri poiklitik ve nematoblastik doku göstermektedir. Porfiroblastik granatlar

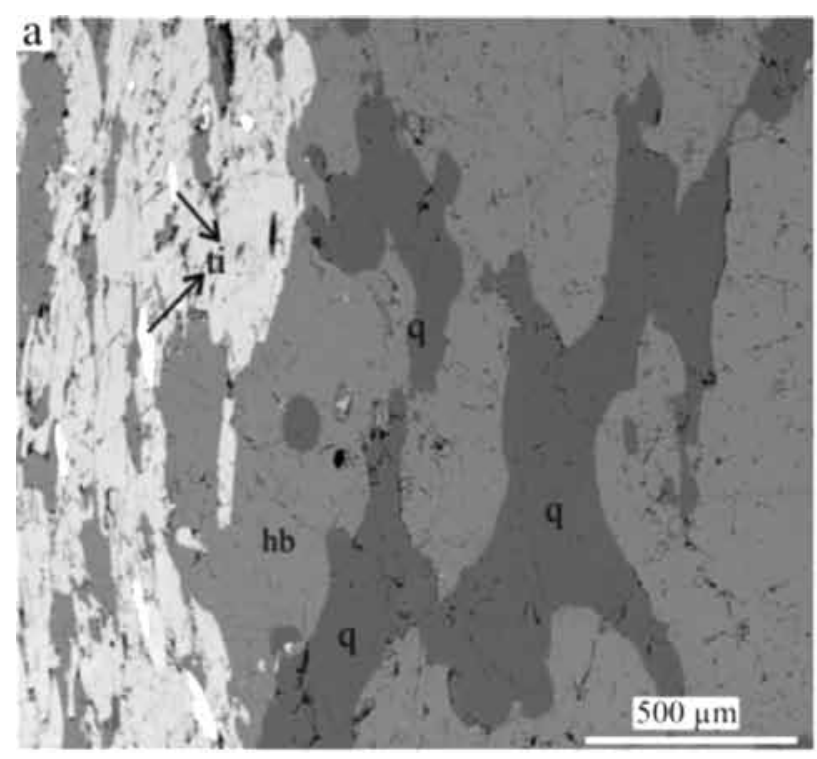

kuvars, epidot ve zirkon kapanımları (inklüzyon) içermektedir. Kuvars taneleri gri, sarı renkte ve öz şekilsiz olarak hem matriks içerisinde hem de granat içerisinde kapanım olarak gözlenmektedir (Şekil 4a). Matriks içerisinde gözlenen kuvars tanelerinin boyları 200-350 $\mu \mathrm{m}$ arasinda değişmektedir. İnklüzyon olarak bulunan kuvars tanelerinin boyları ise $30-50 \mu \mathrm{m}$ arasındadır. Rutil tanelerinde herhangi bir kapanımın varlığı saptanmamıştır. Rutil taneleri ya matriks içerisinde ayrı taneler şeklinde $(80-90 \mu \mathrm{m})$ ya da klinopiroksen ve granat içerisinde kapanım olarak $(<20 \mu \mathrm{m})$ bulunmaktadır. Çoğunlukla koyu kahve renkli olan rutil tanelerinin etrafinda ilmenit büyümeleri gelişmiştir (Şekil 4b). Bazı rutil tanelerinin etrafında ise geri dönüşümü gösteren titanit gözlenmektedir. Granatın kloritepidot-amfibol topluluğu tarafindan ornatılması ve rutilin titanit tarafından çevrelenmesi yeşilşist fasiyesi kayalarına dereceli bir geri dönüşümü göstermektedir.

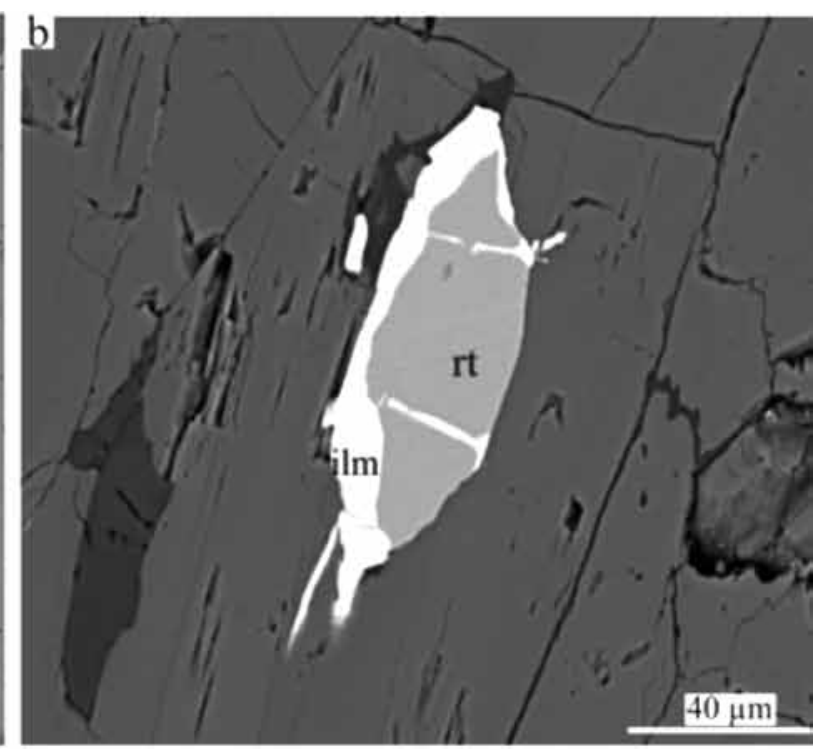

Şekil 4. Dokusal ilişkileri gösteren elektron mikroskobu görüntüleri, a) matriks içerisinde bulunan kuvars (q) mineralleri, b) rutilin kenar kesimlerinde bulunan ilmenit (ilm) oluşumları.

Figure 4. Back scattered electron (BSE) images showing the textural relationships, a) quartz (q) grains occurring in the matrix, b) rutile is surrounded by ilmenite (ilm) rim. 


\section{ÖRNEK HAZIRLAMA VE ANALITIK YÖNTEM}

\section{Örnek Hazırlama}

İz element analizleri için örnekler $50 \mu \mathrm{m}$ kalınlığında parlatılmış ince kesit $(1184,1202)$ ve epoksi içine gömülmüş rutil taneleri $(1130,1301)$ şeklinde hazırlanmıştır. Lazer aşındırma analizleri için analiz yapılacak noktaların belirlenebilmesi için fotoğraflar çekilmiştir. Çekilen bu fotoğraflar lazer aşındırma cihazının örnek yerleştirme haznesi içerisindeki örneklerle yönlendirilmesi yapılmıştır. Bununla birlikte meta-gabrolar içerisindeki rutil taneleri $(1130,1301)$ kırma, eleme, ağır sıvı, manyetik ayırıcı ve binoküler mikroskop altında ayırma ile zenginleştirilmiştir. Bu rutil taneleri iz element analizleri için epoksi içerisine gömülmüş ve parlatılmıştır. Rutil tanelerinin epoksi içerisindeki konumlarının saptanabilmesi için alttan ve üstten aydınlatmalı mikroskopta görüntüleri çekilmiştir. Görüntü ve mineral (BSE) analizleri Göteborg Üniversitesi'nde Hitachi S-3400N taramalı elektron mikroskobu (SEM) kullanarak rutil-kuvars içerisindeki kapanımları tanımlamak ve iz element analizleri için en uygun analiz yerlerini seçmek amacıyla yapılmıştır. Elektron mikroskobunda görüntüleme sırasında analiz koşulları $20 \mathrm{kV}$ ve $6.04 \mathrm{nA}$ olarak ayarlanmıştır. Örnekler BSE-SEM analizleri öncesinde karbonla kaplanmıştır. Analizden sonra ise $1 \mu \mathrm{m}$ alüminyum oksit $\left(\mathrm{Al}_{2} \mathrm{O}_{3}\right)$ tozuyla karbonla kaplanmış örneğin karbonunun çıkarılması ve daha sonra örneğin ultrasonik temizleme banyosunda 5 dakika kalıp tamamen temizlenmesi sağlanmıştır. En son olarak örnek lazer aşındırma cihazının örnek yerleştirme haznesine yerleştirmeden önce etanolle 1slatılmış bir peçeteyle örneğin yüzeyinin tamamen temizlenmesi yapılmıştır.

\section{LA-ICP-MS Analizleri}

Rutil ve kuvars iz element analizleri Göteborg Üniversitesi'nin (İsveç) yer bilimleri bölümünde bulunan epoksi içine gömülmüş rutiller ve parlatılmış ince kesitler üzerinde yapılmıştır. Bütün örnekler Agilent 8800 QQQ dört kutuplu ICP-MS'e monte edilmiş New Wave NWR 213 LA (laser ablation) ile analiz edilmiştir. Sistemde taşıyıcı gaz olarak He-Ar gazı kullanılmıştır. Helyum gazı örneklerin bulunduğu örnek tutucudan lazer ile aşındırılmış örnek partiküllerini taşır ve taşıyıcı gaz olarak Argon ve hassasiyeti artırmak için ilave gaz olarak Nitrojen ile karışarak ICP-MS'in 1s1 kaynağına doğru akar. Helyum aşındırma kabına yaklaşık olarak dakikada $1 \mathrm{ml}$ hızla akar. Helyum aynı zamanda aşınma yüzeyinde birikmeyi önleyerek hassasiyeti artırır ve partiküllerin boyu nedeniyle parçalanmayı azaltır (Eggins vd. 1998).

Analizden önce hem parlatılmış ince kesitler hem de epoksi içine gömülmüş rutiller örnek tutucu içerisinde yerleştirilmiştir. Rutilin iz elementleri $\sim 7.7 \mathrm{~J} / \mathrm{cm}^{2}$ lazer enerjisinde $12 \mu \mathrm{m}$ çapında lazer ışını kullanılarak analiz edilmiştir. $\mathrm{Bu}$ sırada tekrarlama oranı $5 \mathrm{~Hz}$ olarak ayarlanmıştır. Her bir analiz noktası için 60 saniye aralıklarla sinyaller kaydedilmiştir. İlk 20 saniye lazerin ısınması sırasında geri planın analiz edilmesi için kullanılmıştır. İzleyen 30 saniyelik bekleme süresinde lazerin rutili aşındırmasıyla örneğin analiz edilmesi için kullanılmıştır. Son 10 saniye ise temizleme için kullanılmıştır. ${ }^{27} \mathrm{Al},{ }^{51} \mathrm{~V},{ }^{53} \mathrm{Cr}$, ${ }^{57} \mathrm{Fe},{ }^{178} \mathrm{Hf},{ }^{181} \mathrm{Ta},{ }^{232} \mathrm{Th}$ (10 ms bekleme süresi), ${ }^{49} \mathrm{Ti},{ }^{93} \mathrm{Nb}\left(5 \mathrm{~ms}\right.$ bekleme süresi) ve ${ }^{90} \mathrm{Zr},{ }^{238} \mathrm{U}(30$ $\mathrm{ms}$ bekleme süresi) elementleri rutil içerisindeki iz element konsantrasyonlarının belirlenebilmesi için seçilmiştir. Her analiz bloğu iki adet R10 rutil standart analizi ve iki adet NIST SRM 610 cam standardı analizinden oluşmaktadır. Her onbeş rutil analizinden sonra dört standart analizi yapılmıştır. ${ }^{49} \mathrm{Ti}$ olarak ölçülen titanyum (Ti) bütün 
analizler için iç standart elementi olarak ve ${ }^{90} \mathrm{Zr}$ rutil içerisindeki Zr konsantrasyonunu saptamak için kullanılmıştır. Cam referans materyali NIST SRM 610 (Jochum vd. 2006) ve R10 rutil standardı (Luvizotto vd. 2009) diş kalibrasyonu oluşturmaktadır. Kuvarsın iz element analizleri ise $\sim 30 \mathrm{~J} / \mathrm{cm}^{2}$ lazer enerjisinde $50 \mu \mathrm{m}$ çapında lazer ışını kullanılarak analiz edilmiştir. Tekrarlanma oranı ise $4 \mathrm{~Hz}$ olarak kalibre edilmiştir. Toplam analiz zamanı 50 saniye olarak belirlenmiştir. İlk 10 saniye lazer aşındırmasından önce lazerin 1sınması sırasında geri planın analiz edilmesi için kullanılmıştır. Sonraki 30 saniyelik sürede ise lazerin kuvarsı aşındırmasıyla örneğin analiz edilmesi için kullanılmıştır. Son 10 saniye ise cihazın bir sonraki analize hazır olabilmesi amacıyla temizleme için ayrılmıştır. ${ }^{7} \mathrm{Li}$ (09 ms bekleme süresi), ${ }^{23} \mathrm{Na}$ (11 ms bekleme süresi), ${ }^{24} \mathrm{Mg},{ }^{27} \mathrm{Al},{ }^{28} \mathrm{Si},{ }^{48} \mathrm{Ti},{ }^{49} \mathrm{Ti}$ (12 ms bekleme süresi), ${ }^{55} \mathrm{Mn},{ }^{56} \mathrm{Fe},{ }^{57} \mathrm{Fe},{ }^{71} \mathrm{Ga},{ }^{72} \mathrm{Ge}$ (13 ms bekleme süresi) elementleri kuvars içerisindeki iz element konsantrasyonlarının belirlenebilmesi için cihaza tanımlanmıştır. Birinci standard olarak iki adet NIST SRM 610 (Jochum vd. 2006) cam standard1 kullanılmıştır. İkinci standard olarak iki adet BCR-2G (doğal bazaltik cam standard1) (Wilson, 1997) seçilmiştir. Standardlar her 10 analizden sonra tekrar analiz edilmiştir. ${ }^{28} \mathrm{Si}$ bütün analizler için iç standart element olarak kullanılmıştır. Beş farklı Ti izotopu ( ${ }^{46-50} \mathrm{Ti}$ ) vardır. Kuvarsın matriksi lazere maruz kaldığında bir saçılma meydana gelir. Bu saçılma sırasında Ti izotoplarında bir karışma olur ve Si izotoplarının oksitlerine dağılır. $\mathrm{Bu}$ durumdan en az ${ }^{49} \mathrm{Ti}$ izotopu etkilenmektedir. $\mathrm{Bu}$ yüzden analizlerde ${ }^{49} \mathrm{Ti}$ izotopu değerleri kullanılmıştır. Element konsantrasyonları GLITTER 4.4.4 programı kullanarak saptanmıştır (On-line olarak analiz sırasında LA-ICPMS için veri düzeltmesi, van Achterbergh et al. 2000). Bu program ${ }^{7} \mathrm{Li},{ }^{23} \mathrm{Na},{ }^{28} \mathrm{Si},{ }^{48} \mathrm{Ti},{ }^{49} \mathrm{Ti},{ }^{51} \mathrm{~V},{ }^{53} \mathrm{Cr},{ }^{55} \mathrm{Mn}$, ${ }^{56} \mathrm{Fe},{ }^{57} \mathrm{Fe},{ }^{71} \mathrm{Ga},{ }^{72} \mathrm{Ge},{ }^{9} \mathrm{Zr},{ }^{93} \mathrm{Nb},{ }^{95} \mathrm{Mo},{ }^{118} \mathrm{Sn},{ }^{121} \mathrm{Sb}$,
${ }^{178} \mathrm{Hf},{ }^{181} \mathrm{Ta},{ }^{182} \mathrm{~W},{ }^{208} \mathrm{~Pb},{ }^{232} \mathrm{Th},{ }^{238} \mathrm{U}$ izotoplarının ölçülmesine dayalıdır. Veri düzeltmesi sırasında titanyum içeriği $100 \mathrm{wt} \% \mathrm{TiO}_{2}$ ve silisyum içeriği ise $100 \mathrm{wt} \% \mathrm{SiO}_{2}$ olarak kabul edilmiştir.

\section{ANALİZ SONUÇLARI}

\section{Rutilin İz Element Bileşimi}

Rutil tanelerinin iz element konsantrasyonları Çizelge 1'de verilmektedir. Analiz edilen örneklerde dokusal olarak üç farklı tipte rutil bulunmaktadır. Örneklerde $(1184,1202)$ en yaygın olanı matriks içerisinde bulunan rutil olup bu rutilin tane boyu $80 \mu \mathrm{m}$ ile $90 \mu \mathrm{m}$ arasında değişmektedir. Rutil kapanım olarak granat (tane boyu 20-40 $\mu \mathrm{m}$ ) ve klinopiroksen (tane boyu 10-20 $\mu \mathrm{m}$ ) içerisinde bulunur. Ayrıca ofiyolitik meta-gabrolardan $(1130,1301)$ ayırt edilen büyük rutil tanelerinin boyutları $100 \mu \mathrm{m}$ ile $300 \mu \mathrm{m}$ arasındadır. Meta-gabrolar içerisinde dokusal olarak farklı rutil tipleri ve içerdiği $\mathrm{Zr}$ konsantrasyonları Çizelge 2 de özetlenmiştir. Bütün porfiroblastik granat taneleri küçük çatlaklar içerir ve bu çatlaklarda klorit, epidot, biyotit gibi ikincil mineraller bulunmaktadir. $\mathrm{Bu}$ çatlaklar geri dönüşüm sırasında iz elementlerin iletilmesi için olası yolları oluşturmaktadır. 1130 nolu örnekten ayırt edilen rutil tanelerinin $\mathrm{Zr}$ ve Hf içerikleri sırasıyla $176-352 \mathrm{ppm}$ ve $8-14$ ppm arasında değişmektedir. $\mathrm{Nb}$ ve Ta içerikleri ise sirasiyla $120-363 \mathrm{ppm}$ ve $8-28 \mathrm{ppm}$ arasinda değerlere sahiptir. 1184 nolu örnek içerisindeki $\mathrm{Zr}$ ve Hf konsantrasyonları sirasiyla 289-428 ppm ve 10-18 ppm arasındadır. $\mathrm{Nb}$ ve Ta içerikleri ise sirasiyla 748-811 ppm ve 39-49 ppm arasındadir. 1202 nolu örneğin $\mathrm{Zr}$ ve Hf içerikleri sırasıyla 250302 ppm ve 9-11 ppm arasında değişmektedir. $\mathrm{Nb}$ ve Ta konsantrasyonları sirasiyla 721-779 ppm ve 62-73 ppm arasındadır. 1301 nolu örnekten ayırt edilen rutil tanelerinin $\mathrm{Zr}$ ve Hf içerikleri sırasıyla 
176-399 ppm ve 8-15 ppm arasında değerlere sahiptir. Rutil içerisindeki $\mathrm{Nb}$ ve Ta içerikleri sirasiyla $125-336 \mathrm{ppm}$ ve $7-18 \mathrm{ppm}$ arasindadır. Meta-gabro örnekleri içerisindeki rutil tanelerinin $\mathrm{V}$ ve $\mathrm{Cr}$ içerikleri $704-1238 \mathrm{ppm}$ ve $1131-3620$ ppm arasında değişmektedir. Buna karşın 1202 nolu örnekteki rutil tanesi en yüksek Fe içeriğine (6816 ppm) sahiptir.

Rutil tanelerinin geri saçınımlı elektron mikroskobu (BSE) görüntüleri rutiller içerisinde sistematik bir bileşimsel zonlanmanın olmadığını göstermektedir. Rutil taneleri üzerinde birden fazla nokta analizleri yapılmıştır ve bu analizlerde genellikle $\mathrm{Zr}$ dağılımı homojendir (Şekil 5). Bununla birlikte rutillerin bazı yerlerinde, kenar kesimleri Zr'ca daha zengindir (Şekil $5 \mathrm{a}, \mathrm{b})$. Zr'ca zengin fazlar rutil tanelerinde $\mathrm{Zr}$ konsantrasyonlarının değişmesine neden olmaktadır. Önceden var olan ilmenit gibi Zr'ca zengin mineralin rutil tarafından yer değiştirmesi rutil içerisinde Zr'ca zengin fazların oluşumunu açıklayabilmektedir (Austrheim vd. 2008; Meyer vd. 2011).

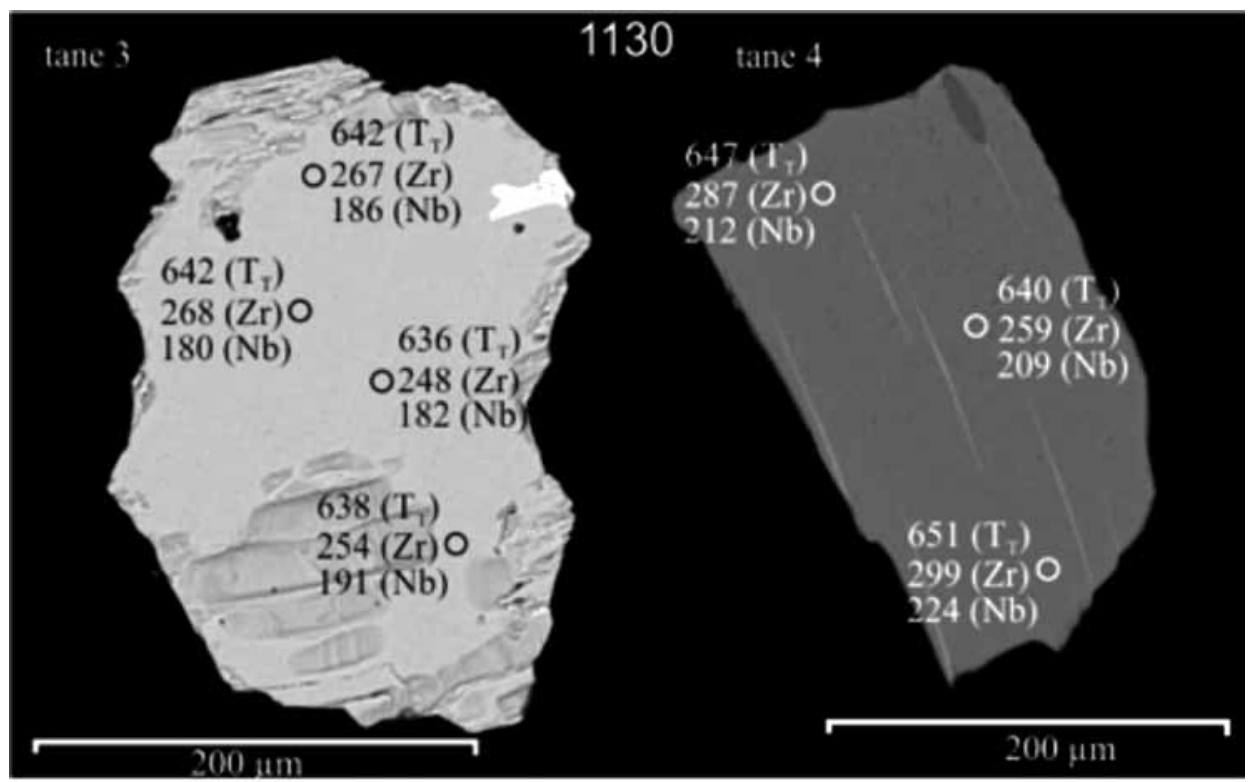

Şekil 5. Çoklu analiz için kullanılan 1130 nolu örnekteki rutil tanelerinin (tane 3 ve tane 4 ) elektron mikroskobu görüntüleri, a, b) rutil taneleri homojen $\mathrm{Zr}$ içeriğine sahiptir fakat kenar kesimlerinde az da olsa $\mathrm{Zr}$ zenginleşmektedir. Rutil içerisinde ilmenit oluşumları bulunmaktadır. Daireler analiz yapılan yerleri göstermektedir. Rakamlar ${ }^{0} \mathrm{C}$ cinsinden sicaklığ 1 göstermekte ve $\mathrm{Zr}-\mathrm{Nb}$ içerikleri ppm cinsinden verilmektedir. Hesaplanan sıcaklıklar Zr'un rutil içerisinde homojen dağılımını göstermekte ve 636-651 ${ }^{0} \mathrm{C}$ arasında değişmektedir.

Figure 5. BSE images of rutile from sample 1130 (grain 3 and grain 4) used for multiple measurements, a, b) Rutile grain with homogeneous $\mathrm{Zr}$ content throughout the grain but the rim is slightly enriched in $\mathrm{Zr}$ content. Ilmenite needles occur in rutile. Circles mark the location of the spots analysed. The numbers give $T_{T}$ in ${ }^{\circ} \mathrm{C}$ and the contents of $\mathrm{Zr}$ and $\mathrm{Nb}$ in ppm. Calculated temperatures vary from 636 to $651{ }^{\circ} \mathrm{C}$ indicating a homogenous distribution of Zr-in-rutile. 
Çizelge 1. Rutilin LA-ICPMS ile saptanan iz element konsantrasyonları ve rutil değerleriyle hesaplanan sıcaklıklar Table 1. LA-ICPMS trace element concentrations and estimated temperatures of rutile by Zr-in-rutile thermometry

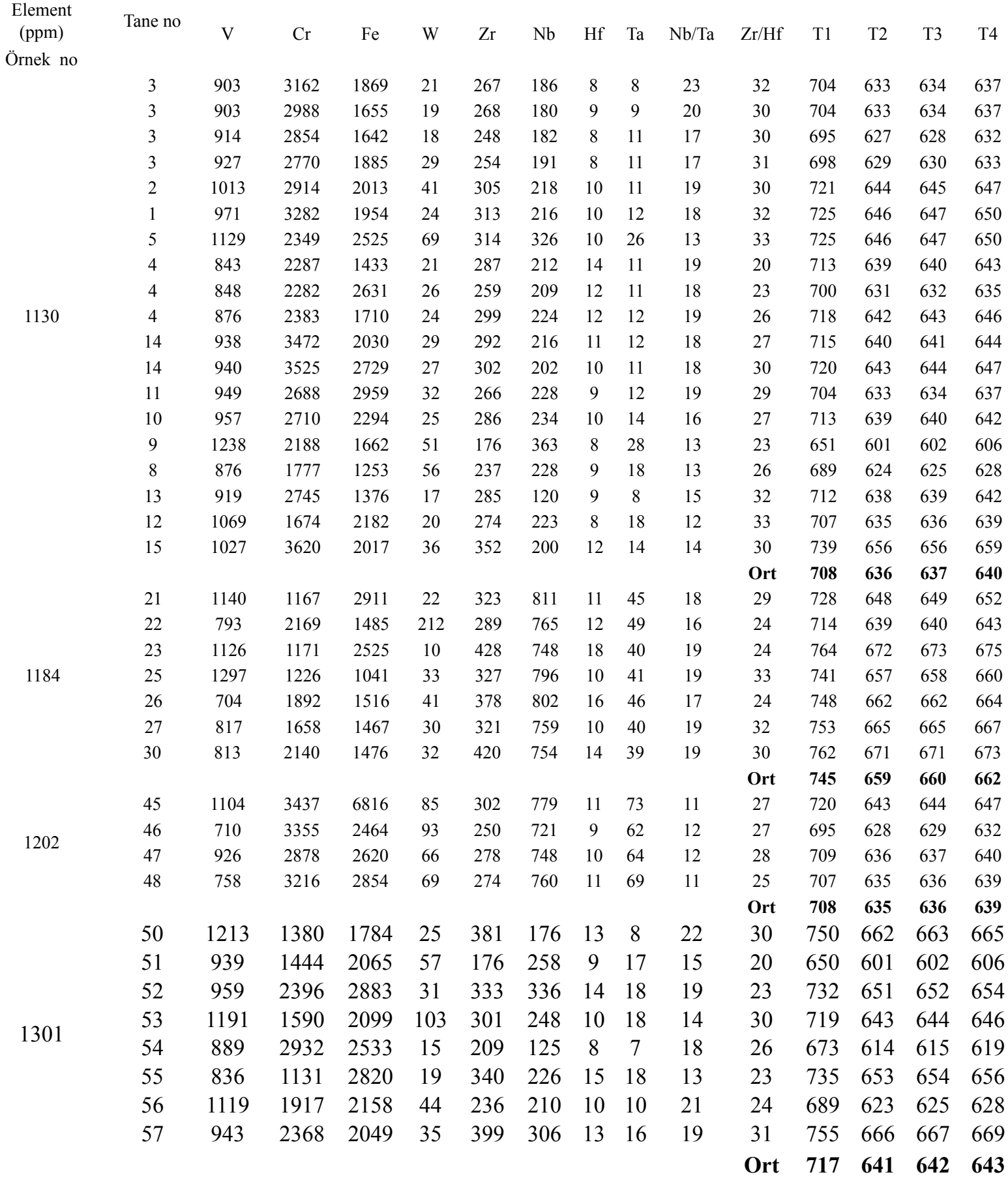

1, 2, 3, 4 sıcaklıklar sırasıyla Zack vd. (2004), Watson vd. (2006), Ferry ve Watson (2007), ve 9 kbar basınçta Tomkins vd. (2007) 
Çizelge 2. Dokusal olarak farklı tipte bulunan rutil tanelerinin $\mathrm{Zr}$ konsantrasyonları

Table 2. $Z r$ concentrations in different textural positions of rutile grains.

Örnek

1184

1202

$\mathrm{Zr}(\mathrm{ppm}) \quad \mathrm{Zr}(\mathrm{ppm})$

$357 \quad 250$

$\begin{array}{lll}\mathrm{Rt}_{\text {matriks }} & 378 & 274\end{array}$

391

$\mathrm{Rt}_{\text {kapnım }}$ (granat)

420

428

302

278
Element oranlarının ve içeriklerinin yayılımı örnekten örneğe değişmektedir. $\mathrm{Nb}$ ve Ta elementlerindeki değişim $\mathrm{Zr}$ ve $\mathrm{Hf}$ elementlerindeki değişime oranla daha belirgindir. $\mathrm{Nb}$ ve Ta pozitif korelasyon sunmaktadır (Şekil 6a). $\mathrm{Zr}$ ve Hf is daha az belirgin pozitif korelasyon göstermektedir (Şekil 6b). Diğer yandan Ta ve Zr iki örnekte $(1202,1130)$ pozitif korelasyon gösterirken 1184 nolu örnek ise negatif korelasyon sunmaktadır (Şekil 6c). 1301 nolu örnek ise saçılmıştır.

$\mathrm{Rt}_{\text {kapanım }}$ (klinopiroksen)
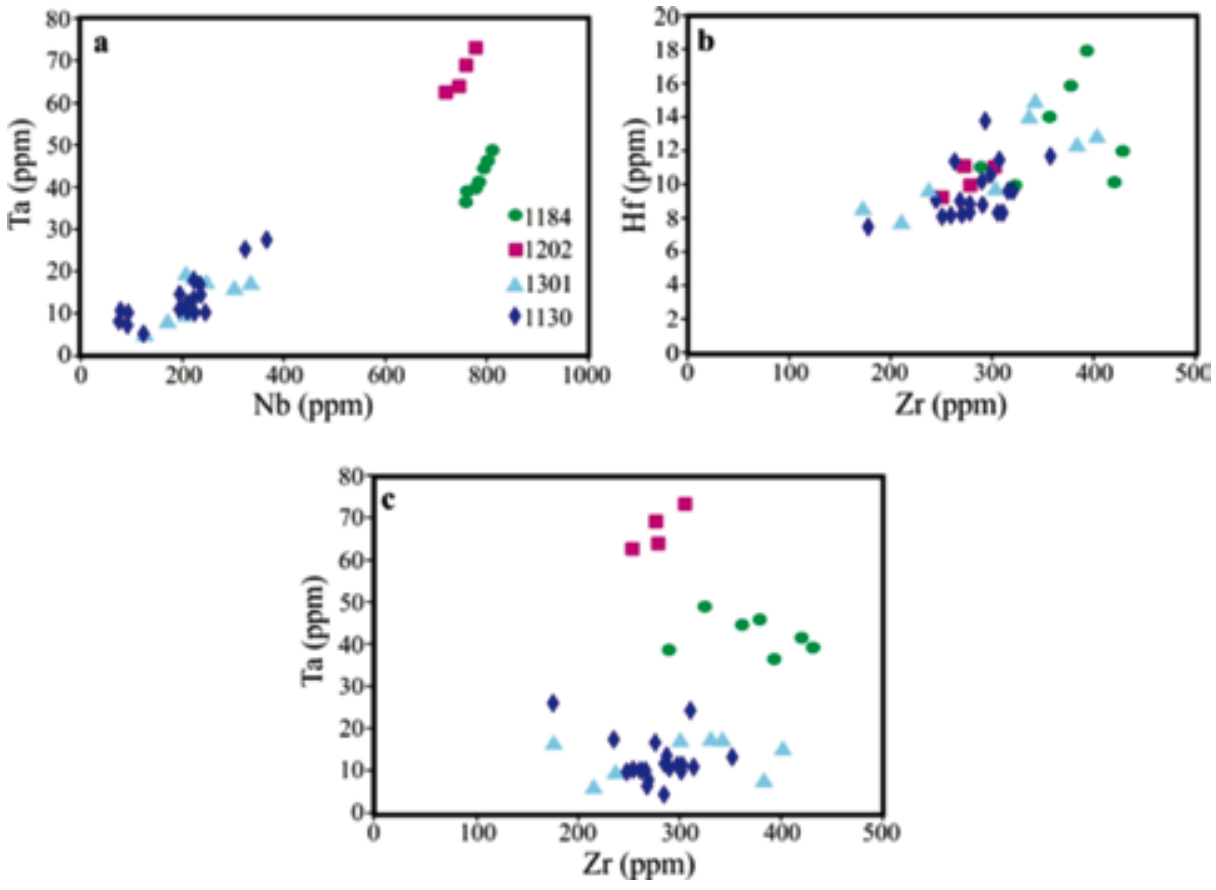

Şekil 6. Kazdağ Masifi'ndeki ofiyolitik meta-gabrolar içerisindeki rutillerin yüksek alan gücüne sahip konsantrasyonlarının değişimini gösteren diyagramlar. Noktalar her bir analizi ifade etmektedir. a, b) kuvvetli pozitif korelasyonu gösteren $\mathrm{Nb}$-Ta diyagramı, b) daha az belirgin pozitif korelasyonu gösteren Zr-Hf diyagramı, c) bir örnek dışında (1202) negatif korelasyonu gösteren Zr-Ta diyagramı.

Figure 6. Results for HFSE concentrations of rutile from ophiolitic meta-gabbros in the Kazdă̆ Massif. Points refer to individual analyses. a) Nb versus Ta indicating a strong positive correlation, $b$ ) $Z r$ versus $H f$ also show positive correlation, but less distinctly, c) Zr versus Ta showing negative correlation except one sample (1202). 
Ta ve Hf konsantrasyonlarında azalma gözlenirken $\mathrm{Nb} / \mathrm{Ta}$ ve $\mathrm{Zr} / \mathrm{Hf}$ oranları artış göstermektedir (Şekil 7a, b). Rutil bileşimleri genellikle 11-19 arasında değişen subkondritik Nb/ Ta değerlerine (kondritik değer 19.9, Münker vd. 2003) ve 20-33 arasında değişen $\mathrm{Zr} / \mathrm{Hf}$ değerlerine (kondritik değer $34.3 \pm 0.3$, Münker vd. 2003) sahiptir (Şekil 7c). Bununla birlikte 1301 nolu ve 1130 nolu örnekten iki rutil tanesi suprakondritik $\mathrm{Nb} / \mathrm{Ta}$ ve $\mathrm{Zr} / \mathrm{Hf}$ değerlerine sahiptir.

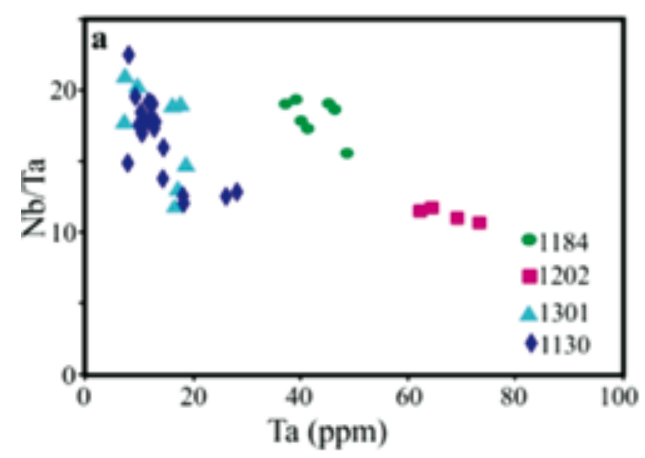

Rutil tanelerinin Zr içerikleri 176 ppm ile 428 ppm arasında değişmektedir. Rutil sıcaklıkları Zack vd. (2004), Watson vd. (2006), Ferry ve Watson (2007), ve Tomkins vd. (2007) tarafindan geliştirilen $\mathrm{Zr}$ içeriklerine bağlı rutil termometreleriyle hesaplanmıştır. Zack vd. (2004) tarafindan önerilen kalibrasyon 708-745 ${ }^{\circ} \mathrm{C}$ (ortalama $720{ }^{\circ} \mathrm{C}$ ) rutil sicaklıkları vermektedir. $\mathrm{Bu}$ sicaklık değerleri diğer kalibrasyonlarla elde edilen sicaklık değerlerinden daha yüksektir. Watson vd. (2006) tarafindan önerilen kalibrasyon

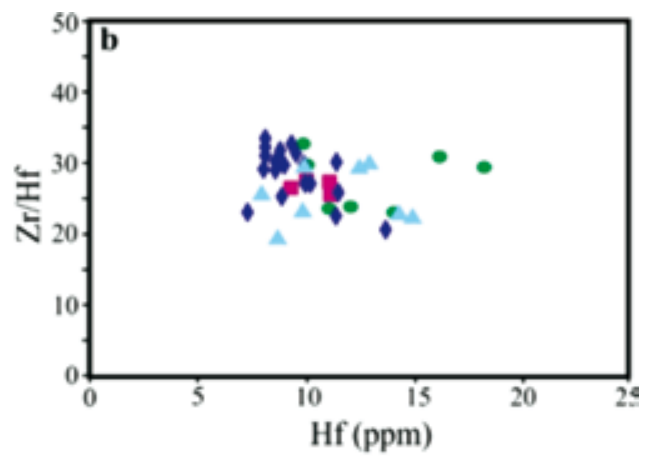

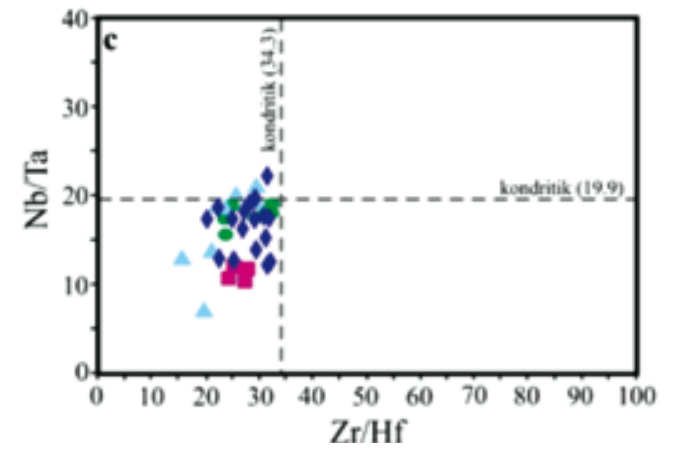

Şekil 7. Element oranlarını gösteren diyagramlar. Noktalar her bir analizi ifade etmektedir. a) Ta-Nb/Ta diyagram1, b) Hf-Zr/Hf diyagramı, c) Zr/Hf-Nb7Ta diyagramı. Rutilin Nb7Ta ve Zr/Hf oranları genellikle subkondritiktir. Kesikli çizgiler $\mathrm{Nb} / \mathrm{Ta}$ ve $\mathrm{Zr} / \mathrm{Hf}$ için kondritik değerleri ifade etmektedir (Münker vd. 2003).

Figure 7. Element ratio plots. Points represent individual analyses. (A) Ta versus Nb/Ta. (B) Hf versus Zr/Hf. (C) $\mathrm{Zr} / \mathrm{Hf}$ versus $\mathrm{Nb} / \mathrm{Ta}$ diagram. Generally $\mathrm{Nb} / \mathrm{Ta}$ and $\mathrm{Zr} / \mathrm{Hf}$ of rutile are subchondritic. Dashed lines refer to chondritic values for $\mathrm{Nb} / \mathrm{Ta}$ and $\mathrm{Zr} / \mathrm{Hf}$ (Münker et al. 2003).

\section{Rutil Termometresi ve Klasik \\ Jeotermobarometre}

Ofiyolitik meta-gabroların Zr konsantrasyonları ve bununla ilişkili olarak rutil termometresinden elde edilen sıcaklıklar Çizelge 1'de verilmektedir. kullanılarak hesaplanan sicaklıklar $635{ }^{\circ} \mathrm{C}$ ile $659{ }^{\circ} \mathrm{C}$ arasında (ortalama $643{ }^{\circ} \mathrm{C}$ ) değişmektedir. Ferry ve Watson (2007) kalibrasyonu ile elde edilen rutil sicakl1kları $636-660{ }^{\circ} \mathrm{C}$ (ortalama 644 ${ }^{\circ} \mathrm{C}$ ) arasindadir. Watson vd. (2006) ve Ferry ve 
Watson (2007) termometrelerinden hesaplanan sicaklılar birbirine benzerdir. Tomkins vd. (2007) tarafından önerilen rutil termometresi ise basınca bağımlıdır. Bu kalibrasyonda basınç değeri olarak daha önce klasik yöntemlerle hesaplanmış olan basınç değeri kullanılmıştır. Buna göre granatbiyotit Fe-Mg değişim termometresi (Ferry ve Spear, 1978) ve granat-plajioklas-hornblendkuvars jeobarometresiyle (Kohn ve Spear, 1990) meta-gabrolar için basınç-sıcaklık değerleri 9 kbar ve $665 \pm 25^{\circ} \mathrm{C}$ olarak hesaplanmıştır (Şengün ve Zack, 2016). 9 kbar basinçta Tomkins vd. (2007) tarafından önerilen rutil termometresi 639-662 ${ }^{\circ} \mathrm{C}$ (ortalama $646{ }^{\circ} \mathrm{C}$ ) arasında değişen sıcaklıklar vermiştir.

\section{Kuvars Termometresi}

Kuvarsin iz element analizleri ve TitaniQ termometresiyle hesaplanan sicaklık değerleri Çizelge 3 de verilmiştir. 1184 nolu örnek içerisindeki kuvarsın Ti içeriği 36-42 ppm arasında değişmektedir. Buna karşın 1202 nolu örnekteki kuvarsın Ti içeriği ise 28 ppm ile 35 ppm arasındadır. Kuvarsın kristalizasyon sicaklıkları kuvarsın Ti içeriğine göre geliştirilen TitaniQ termometresiyle hesaplanmıştır. $\mathrm{Bu}$ termometrede her fazdaki rutil dengesi ve Ti aktivitesini dikkate alınmaktadır. Kuvars sıcaklıkları Wark ve Watson (2006) tarafından geliştirilen kuvars termometresine göre $623-645{ }^{\circ} \mathrm{C}$ (ortalama 634 ${ }^{\circ} \mathrm{C}$ ) arasında değişmektedir. Bu sıcaklık değerleri kuvarsın kristalizasyon sicaklıklarını ifade etmektedir. Bununla birlikte Thomas vd. (2010) tarafından geliştirilen kalibrasyon basıncın kuvars içerisindeki Ti üzerine etkisini dikkate almıştır. Buna göre ofiyolitik meta-gabroların basınçsıcaklık değerleri sınırlandırılmaktadır (Şekil 8). Ortalama $\mathrm{Zr}$ ve Ti değerleri sırasıyla $335 \mathrm{ppm}$ ve 36 ppm dir. Şekil 8'de kuvarsın Ti içerikleri ve rutilin $\mathrm{Zr}$ içeriklerine ait eş değer eğrileri basınç- sıcaklık diyagramına aktarılmıştır. Ofiyolitik meta-gabro örneklerinin basınç-sıcaklık değerleri kuvarsın Ti içeriğine ait eş değer eğrisi ile rutilin $\mathrm{Zr}$ içeriğine ait eş değer eğrisinin kesişmesinden elde edilmiştir. Buna göre Thomas vd. (2010) kalibrasyonu kullanılarak hazırlanan basınçsicaklık diyagramında ofiyolitik meta-gabroların kristalizasyon koşulları $10 \mathrm{kbar}$ ve $660^{\circ} \mathrm{C}$ olarak saptanmıştır.

Çizelge 3. Kuvarsın LA-ICPMS ile saptanan iz element konsantrasyonları ve Ti değerleriyle hesaplanan sicaklıklar

Table 3. LA-ICPMS trace element concentrations and estimated temperatures of quartz by Ti-in-quartz thermometry

$\begin{array}{cc}\text { Element } & \text { Tane } \\ (\mathrm{ppm}) & \text { no }\end{array}$ Li Na $\quad \mathrm{Mg}$ Al $\mathrm{Ti}$ Mn Fe $\begin{gathered}\mathrm{T} 1 \\ \left({ }^{\circ} \mathrm{C}\right)\end{gathered}$

Örnek no

1184

$\begin{array}{cclcccccc}114 & 5 & 22 & 20 & 27 & 41 & 1 & 16 & 650 \\ 115 & 3 & 20 & 13 & 43 & 36 & 3 & 61 & 638 \\ 116 & 5 & 9 & 16 & 46 & 38 & 1 & 7 & 643 \\ 117 & 4 & 9 & 27 & 54 & 39 & 1 & 19 & 646 \\ 118 & 3 & 12 & 12 & 31 & 40 & 1 & 4 & 648 \\ 119 & 4 & 8 & 22 & 98 & 42 & 1 & 40 & 653 \\ 120 & 4 & 14 & 28 & 26 & 38 & 1 & 32 & 643 \\ 121 & 4 & 15 & 19 & 61 & 36 & 1 & 54 & 638 \\ 122 & 3 & 8 & 14 & 50 & 39 & 1 & 22 & 646 \\ & & & & & & & \text { Ort } 645\end{array}$

$\begin{array}{rrrrrrrrrr} & 122 & 4 & 9 & 7 & 78 & 30 & 1 & 90 & 621 \\ 1202 & 123 & 5 & 22 & 7 & 39 & 33 & 2 & 91 & 624 \\ & 124 & 5 & 11 & 2 & 67 & 32 & 1 & 60 & 627 \\ & 125 & 4 & 7 & 9 & 42 & 28 & 2 & 84 & 608 \\ 126 & 5 & 8 & 6 & 47 & 34 & 3 & 51 & 633 \\ 127 & 7 & 9 & 1 & 32 & 35 & 1 & 61 & 624 \\ & & & & & & & & \text { Ort } & \mathbf{6 2 3}\end{array}$

1 Sicaklıklar Wark ve Watson (2006) kalibrasyonuna göre hesaplanmıştır 


\section{TARTIŞMA}

\section{Rutilin İz Element Bileşimi}

Rutil içerindeki $\mathrm{Nb}$ ve Ta toplam kayanın $\mathrm{Nb}$ ve Ta içeriklerinin büyük bir kısmını oluşturmakta ve rutilin $\mathrm{Nb}$ /Ta oranı toplam kayanın $\mathrm{Nb}$ /Ta oranıyla benzerdir. Ofiyolitik meta-gabro örnekleri içerisindeki rutil taneleri yüksek oranda $\mathrm{Nb}$ (180811 ppm), Ta (8-73 ppm), Zr (176-428 ppm), Hf (8-18 ppm) ve W (10-103 ppm) gibi yüksek alan gücüne sahip element içeriklerine sahiptir. Aynı zamanda V (704-1238 ppm) ve Cr (1131-3620 ppm) gibi yüksek oranda geçiş metal elementleri içerirler. Diğer iz elementleri ise ya düşük konsantrasyonda ya da sınır değerlerin altındadır. Bununla birlikte 1202 nolu örnek içerisindeki bir rutil tanesi en yüksek Fe içeriğine (6816 ppm) sahiptir. Yüksek Fe içeriği olasılıkla rutil içerisinde bulunan ince ilmenit şeklinde mineral kapanımlarından ya da demir oksit lamellerinden kaynaklanmaktadır. 1184 ve 1202 nolu meta-gabro örnekleri en yüksek Nb ve Ta içeriklerine sahiptir. Buna karşın 1130 ve 1301 nolu meta-gabro örnekleri ise en düşük Nb ve Ta konsantrasyonları içermektedir (Çizelge 1, Şekil 6a). Bu da daha yüksek Ti içerikli minerallerin benzer iyon yarıçapı ve Nb, Ta ve Ti'un benzer değerliğe sahip olması nedeniyle $\mathrm{Nb}$, Ta elementlerinin davranışı üzerine daha büyük etkiye sahip olduğunu göstermektedir (Horng ve Hess, 2000; Schmidt vd. 2004).

Rutil tanelerinin kenar ve çekirdeklerindeki $\mathrm{Nb} / \mathrm{Ta}$ oranları bir örnekte birbirinden farklıdır. 1130 nolu örnekteki rutil tanelerinin çekirdekleri genellikle daha düşük $\mathrm{Nb} / \mathrm{Ta}$ oranlarıyla (17-18) karakterize olurken kenar kesimleri göreceli olarak daha yüksek $\mathrm{Nb} / \mathrm{Ta}$ oranlarına (19-23) sahiptir. Rutil tanelerinin daha yüksek $\mathrm{Nb} / \mathrm{Ta}$ oranlarına sahip kenar kesimlerinde $\mathrm{Nb}$ ve Ta'un zenginleşmesi biyotit gibi sulu minerallerin bozulmasından kaynaklanabilmektedir (Stepanov ve Hermann,
2013). Deneysel verilere dayanarak rutil içindeki $\mathrm{Nb}$ ve Ta'un bölünme katsayılarında $\mathrm{D}_{\mathrm{Nb}}$ daima yitim süreçlerinde $\mathrm{D}_{\mathrm{Ta}}$ 'dan daha düşüktür (Schmidt vd. 2004; Klemme vd. 2005). Deneysel çalışmalar rutil ve akışkan/ergiyik arasında $\mathrm{Nb}$ ve Ta'un ayrılmasının $\mathrm{D}_{\mathrm{Nb} / \mathrm{Ta}}>1$ 'den büyük olduğunu göstermektedir (örn. Brenan vd. 1994; Stalder vd. 1998; Xiong vd. 2005; Xiao vd. 2006). Eğer rutil ergiyik ile dengedeyse bu rutilin başlangıçtaki büyümesinde düşük $\mathrm{Nb} / \mathrm{Ta}$ oranlarına neden olmaktadır (Schmidt vd. 2009). Bu yüzden $\mathrm{Nb} /$ Ta farklılaşması rutilin gelişimi sırasında rutil içerisindeki $\mathrm{Nb}$ ve Ta'un birbiriyle uyumunu belirtmektedir. $\mathrm{Bu}$ durum yitim zonlarındaki metamorfik dehidrasyon sirasinda $\mathrm{Nb} / \mathrm{Ta}$ farklılaşmasının temel sonucu olabilmektedir. Akışkan hareketliliği akışkan ve rutil arasında $\mathrm{Nb}$ ve Ta'un ayrılmasında etkili rol oynamaktadır.

$\mathrm{Nb} / \mathrm{Ta}$ ve $\mathrm{Zr} / \mathrm{Hf}$ pozitif korelasyon sunmaktadır. Kitasal kabuk, volkanik kayalar, okyanus bazaltları ve ada yayları subkondritik $\mathrm{Nb} / \mathrm{Ta}$ oranlarıyla karakterize olmaktadır (Green, 1995; Rudnick vd. 2000; Foley vd. 2002; Schmidt vd. 2009). Subkondritik Nb/Ta oranları orta-yüksek dereceli metamorfik bölgelerdeki (örn. Meyer vd. 2011; Luvizotto ve Zack, 2009; Ewing vd. 2013) ve yüksek basınç metamorfik bölgelerindeki rutillerde bulunmaktadır (Xiao vd. 2006; John vd. 2011; Huang vd. 2012). Nb/ $\mathrm{Ta}$ ve $\mathrm{Zr} / \mathrm{Hf}$ oranları Ta ve Hf içeriklerindeki azalmayla artma eğilimi göstermektedir (Şekil $7 \mathrm{a}, \mathrm{b}) . \mathrm{Bu}$ nedenle Ta içeriği azalırken $\mathrm{Nb} / \mathrm{Ta}$ oranının artması yitim zonlarındaki metamorfik dehidrasyonun rutil $\mathrm{Nb} / \mathrm{Ta}$ ayrımlaşması üzerine etkisine bağlanabilmektedir (Schmidt vd. 2009; Gao vd. 2014). Dehidrasyon metamorfizmas1 yitim süreçlerinde rutil oluşumu için yaygın bir mekanizmadır. $\mathrm{Nb}$ ve Ta aynı oksidasyon evresine ve benzer iyon yarıçaplarına sahip olduklarından dolayı kabuk-manto ayrımlaşma sisteminde 
jeokimyasal süreçler sırasında birleşik olarak bulunurlar. Bununla birlikte kütlelerinde önemli bir fark vardır ve bu da jeokimyasal süreçler sırasında $\mathrm{Nb} / \mathrm{Ta}$ ayrımlaşmasının potansiyel nedenini oluşturmaktadır.

Rutilin iz element analizleri rutil tanelerinin metamorfik akışkanlardan itibaren geliştiğini göstermektedir. Yitim zonlarında üç tip jeoakışkan vardır. Bunlar; sulu ergiyik, sulu çözelti ve süper kritik akışkandır. Bunlar iz elementlerin çözünmesinde ve taşınmasında farkl1 roller oynamaktadır (Hermann vd. 2006; Zheng vd. 2011). Genellikle hafif nadir toprak elementleri ve orta nadir toprak elementleri gibi suda çözülmeyen uyumsuz iz elementler sulu ergiyik vasıtasıyla düşük iyonlu litofil elementlerle birlikte çözülebilmekte ve taşınabilmektedir. Düşük iyonlu litofil elementleri gibi suda çözülebilir uyumsuz iz elementler sulu çözeltiler içinde hareketlidir. Ağır nadir toprak elementleri ve yüksek alan gücüne sahip elementler gibi uyumsuz elementler yitim zonlarında amfibolityüksek basınç metamorfizma koşulları altında süperkritik akışkanla çözülebilmekte ve taşınabilmektedir (örn. Tatsumi ve Nakamura, 1986; Scambelluri vd. 2001; John vd. 2004; Hermann vd. 2006; Xia vd. 2010; Zheng vd. 2011; Gao vd. 2014). Ayrıca okyanusal kabuğun yitimi ve yüzeylemesi sırasında farklı bileşimde metamorfik akışkanlardan rutil gelişebilmektedir. Bunun nedeni ise sulu minerallerin bozulması ve sulu minerallerin bozulması da orta-yüksek dereceli metamorfik kayalarda sulu çözeltiler için baskın bir kaynak oluşturmaktadır.

\section{Basınç-Sıcaklık Koşulları}

Kazdağ Masifi'nde yüzlek veren meta-ofiyolitik kayaların basınç-sıcaklık koşulları klasik jeotermobarometre kullanılarak 9 kbar ve
$665 \pm 25{ }^{\circ} \mathrm{C}$ olarak saptanmıştır (Şengün ve Zack, 2016). Bununla birlikte zirkon termometresi klasik termometrelerle karşılaştırıldığında metaofiyolitik kayalar için daha kesin sıcaklık değerleri vermektedir. Sicaklık hesaplamaları için zirkon termometresiyle ilgili Zack vd. (2004), Watson vd. (2006), Ferry ve Watson (2007), ve Tomkins vd. (2007) tarafindan geliştirilen dört farklı kalibrasyon uygulanmıştır. Deneysel ve rutilkuvars-zirkon topluluğuna sahip doğal örneklere dayalı olarak uygulanan bütün kalibrasyonlar Zack vd. (2004) kalibrasyonu dışında benzer sıcaklık aralıkları vermiştir (Şekil 9). Zack vd. (2004) tarafından geliştirilen rutil termometresi 708-745 ${ }^{\circ} \mathrm{C}$ arasında değişen rutil sıcaklıkları vermektedir. $\mathrm{Bu}$ sicaklıklar diğer kalibrasyonlarla hesaplanan sıcaklık değerlerinden daha yüksektir (örn. Miller vd. 2007; Baldwin ve Brown, 2008; Meyer vd. 2011). Bu çalışmada bu kalibrasyonla hesaplanan sicaklıklar bu gözlemi desteklemektedir. Daha sonra Watson vd. (2006), Ferry ve Watson (2007) ve Tomkins vd. (2007) tarafından geliştirilen termometreler daha geniş sıcaklık ve basınç aralıklarında daha doğru değerler vermektedir. Watson vd. (2006) rutil termometresi temel olarak deneysel ve doğal sonuçlara dayalıdır. Watson vd. (2006) tarafından önerilen kalibrasyon kullanılarak hesaplanan sicaklıklar 635-659 ${ }^{\circ} \mathrm{C}$ arasında değişmektedir. Diğer yandan Ferry ve Watson (2007) deneysel çalışmalarında silika aktivitesinin rolünü tanımlamıştır. Rutil içerisindeki Zr konsantrasyonu sadece sicaklığa bağımlı değildir aynı zamanda $\mathrm{SiO}_{2}$ 'nin aktivitesine karşı son derece hassastır. Ferry ve Watson (2007) kalibrasyonu 636-660 ${ }^{\circ} \mathrm{C}$ sicaklik değerleri vermektedir. Watson vd. (2006) ve Ferry ve Watson (2007) tarafindan yapılan deneysel çalışmalar 10 kbar'lık benzer basınç koşullarında gerçekleştirilmiştir. Bu yüzden iki kalibrasyondan elde edlen sicaklık sonuçları birbirleriyle benzerdir. Tomkins vd. (2007) tarafindan önerilen 
kaibrasyon basınç faktörünün de dikkate alındığı bir rutil termometresidir. Bu yüzden Tomkins vd. (2007) tarafindan önerilen rutil termometresi ortayüksek derecel metamorfik kayalar için güvenilir bir termometredir ve klasik termometrelerden daha doğru sicaklık değerleri vermektedir (örn. Spear vd. 2006; Miller vd. 2007; Luvizotto ve Zack, 2009). Ayrıca basınç düzeltmesinin önemi sadece daha yüksek basıncta metamorfizmaya uğramış kayalar için değil aynı zamanda daha düşük basınçta metamorfizmaya uğramış kayalar içinde ihmal edilmemelidir. 9 kbar basınçta Tomkins vd. (2007) tarafindan önerilen rutil termometresi ofiyolitik meta-gabrolar için $639-662{ }^{\circ} \mathrm{C}$ (ortalama $646^{\circ} \mathrm{C}$ ) arasında değişen sıcaklıklar vermiştir.

Çoğu metamorfik kaya kuvars ve rutil mineralleri içermektedir. Bu yüzden kuvarsın Ti içeriğinin basınç-sıcaklığa olan bağımlılığı rutil içerisindeki Zr'un basınç-sıcaklığa olan bağımlılığıyla birleştirildiğinde orta-yüksek dereceli metamorfik kayaların basınç-sıcaklığı hesaplanabilmektedir. Diğer yandan TitaniQ termometresinin basınca olan bağımlılığı metagabrolar için sağlam bir barometre oluşturmaktadır. Meta-ofiyolitik kayaların basınç-sıcaklık koşulları rutil içeren iki meta-gabro örneğindeki (1130 ve 1202 nolu örnekler) rutillerin $\mathrm{Zr}$ içerikleriyle aynı örneklerden elde edilen kuvarsın Ti analizleriyle saptanmıştır (Şekil 8). Meta-gabroların basınçsıcaklık diyagramında kuvarsın Ti içeriği ile rutilin $\mathrm{Zr}$ içeriği eş değer eğrisi olarak aktarılmıştır. Kuvars ve rutil kristallerinin her ikisinin de maksimum metamorfizma koşullarında denge olduğu varsayılırsa eş değer eğrilerinin kesiştiği nokta ortalama basınç-sıcaklık değerlerini vermektedir. Buna göre Kazdağ Masifi'nde yüzlek veren meta-ofiyolitik kayalar için hesaplanan maksimum basınç-sıcaklık koşulları 10 kbar ve $660{ }^{\circ} \mathrm{C}$ olarak saptanmıştır. $\mathrm{Bu}$ basınç-sıcaklık koşulları Tomkins vd. (2007) tarafından geliştirilen rutil termometresiyle ve klasik termometreyle elde edilen basınç-sıcaklık koşullarıyla uyumludur. TitaniQ termometresi diğer bütün termometrelere oranla daha sınırlı ve kesin sonuçlar vermektedir. Diğer yandan metaofiyolitik kayaların çevresinde bulunan felsik gnaysların klasik yöntemlerle hesaplanan basınçSıcaklık koşulları $5 \pm 1$ kbar ve $640 \pm 50{ }^{\circ} \mathrm{C}$ olarak saptanmıştır (Okay ve Satır, 2000). Bu basınçsıcaklık koşulları Kazdağ Masifi'nde yüzlek veren metamorfik kayaların amfibolit fasiyesinde metamorfizma geçirdiğini göstermektedir. Rutil termometresi ve TitaniQ termometresiyle hesaplanan sicaklık değerleri meta-ofiyolitik kayaların çevresinde bulunan orta-yüksek dereceli metamorfik kayaların klasik yöntemlerle hesaplanan sicaklık değerleriyle uyumludur. Bununla birlikte ofiyolitik meta-gabroların basınç değerleri bu kayaların çevresinde bulunan ortayüksek dereceli metamorfik kayaların basıncından daha yüksektir. $\mathrm{Bu}$ da meta-ofiyolitik kayaların Kazdağ Masifi içerisinde ayrı bir tektonik dilim olduğunu ve basınç hesaplamalarına göre yaklaşık $35 \mathrm{~km}$ de amfibolit fasiyesi metamorfizmas geçirdiğini işaret etmektedir. Halbuki Kazdağ Masifi'nde yüzlek veren metamorfik kayalar yaklaşık $20 \mathrm{~km}$ de amfibolit fasiyesi metamorfizması geçirmiştir. Metamorfizma Neo-Tetis okyanusunun İzmir-Ankara kolunun kuzeye Sakarya Zonu altına dalmasından kaynaklanmaktadır. Metamorfizmanın hemen arkasından Kazdağ Masifi'nin orta-yüksek dereceli metamorfik kayaları kendi içerisinde çarpışma sırasında güneye doğru sıkışmayla birbiri üzerine bindirmiştir. Birbiri üzerine bindirmeler sırasında meta-ofiyolitik kayalar ayrı bir tektonik dilim olarak yerleşmiştir. Sakarya Zonu'nun Anatolid-Torid Bloğuyla çarpışması ve Kazdağ Masifi'nin içsel olarak birbiri üzerine bindirmeli yap1 oluşturması kabukta gelişen bir kalınlaşmaya neden olmuştur. 


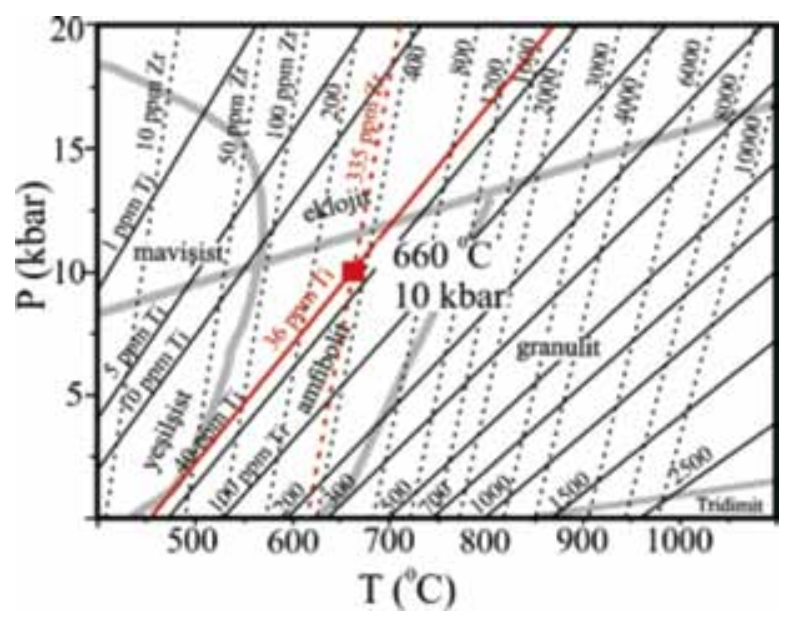

Şekil 8. Kuvarsın $\mathrm{Ti}$ ve rutilin $\mathrm{Zr}$ içeriğine bağlı eş değer eğrilerinin Kazdağ Masifi'ndeki ofiyolitik meta-gabrolar için termobarometre olarak kullanılmasını gösteren diyagram. Yaklaşık metamorfik fasiyesler Spear (1993) ve Philpotts (1990) dan alınmıştır.

Figure 8. Ti-in-quartz and Zr-in-rutile isopleths for usage as a thermobarometer to ophiolitic meta-gabbros in the Kazda $\breve{g}$ Massif. Approximate metamorphic facies are generalized from Spear (1993) and Philpotts (1990).

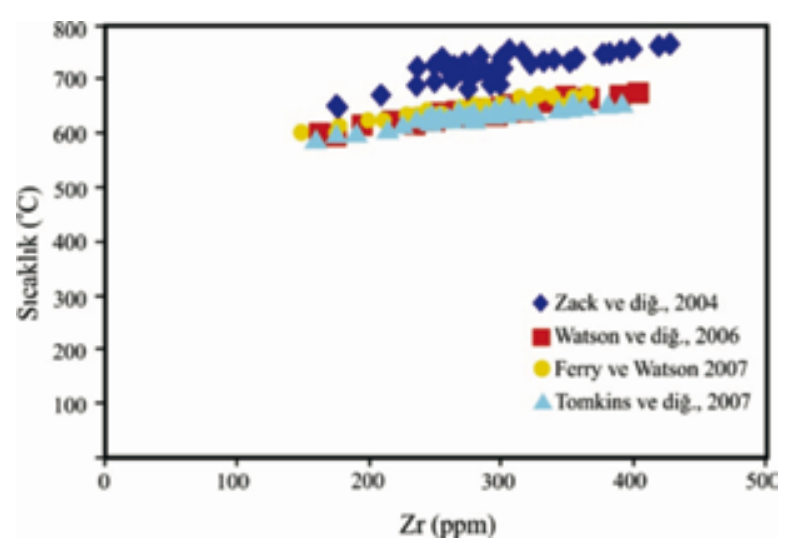

Şekil 9. Çeşitli kalibrasyonlar kullanarak rutil termometresiyle hesaplanan sicaklık değişimlerinde gözlenen farklılık.

Figure 9. Difference in calculated temperature range of the Zr-in-rutile thermometer using various calibrations.

\section{SONUÇLAR}

Kuzeybatı Türkiye'de meta-ofiyolitik kayalar Biga Yarımadası'nın güney kesiminde yer alan Kazdağ Masifi'nde yüzlek vermektedir. Metaofiyolitik kayaların içerisinde baskın litolojiyi oluşturan meta-gabrolardan ayırt edilen rutil taneleri subkondritik $\mathrm{Nb} / \mathrm{Ta}$ ve $\mathrm{Zr} / \mathrm{Hf}$ oranlarıyla karakterize olmaktadır. $\mathrm{Nb} / \mathrm{Ta}$ ve $\mathrm{Zr} / \mathrm{Hf}$ oranları $\mathrm{Nb}$ ve Ta içeriklerinin azalmasıyla birlikte artmaktadır. Bu durum metamorfik dehidrasyonun rutilin $\mathrm{Nb} / \mathrm{Ta}$ ayrımlaşması üzerinde etkili olduğunu işaret etmektedir. Rutilin iz element analizleri rutilin metamorfik akışkanlardan itibaren geliştiğini ifade etmektedir. Yüksek $\mathrm{Nb}$ / Ta oranına sahip sulu akışkanlar yitime uğramış okyanusal kabuğun yüzeylemesi sirasinda biyotitin bozulması nedeniyle metamorfik dehidrasyon nedeniyle oluşmuştur. Diğer yandan rutil tanelerinin kenar kesimlerinde $\mathrm{Nb}$ ve $\mathrm{Ta}$ zenginleşmesi az da olsa $\mathrm{Nb} / \mathrm{Ta}$ oranının artmasıyla sonuçlanmaktadır. Rutilin kenar kesimlerinde $\mathrm{Nb}$ ve Ta zenginleşmesi metamorfik akışkanlar içerisindeki suda çözülemeyen uyumsuz iz elementlerin yerel olarak zenginleşmesini göstermektedir. $\mathrm{Bu}$ iz elementlerin yüzeyleme sırasında süperkritik akışkanlardan ayrılan fazların ürünü olabilmektedir.

Kazdağ Masifi'nde yüzlek veren metaofiyolitik kayaların basınç ve sıcaklık koşullarının belirlenebilmesi için TitaniQ ve rutil termometresi kuvars, rutil ve zirkon içeren meta-gabrolara uygulanmıştır. Sıcaklık hesaplamaları için dört farklı rutil termometresi kullanılmıştır. Basınç faktörünün etkili olduğu Tomkins vd. (2007) kalibrasyonu sadece metamorfizma sicaklıklarının hesaplanması için seçilmiş en iyi termometredir. Kazdağ Masifi'nde yüzlek veren meta-ofiyolitik kayaların metamorfizma sıcaklığı Tomkins vd. (2007) tarafindan önerilen rutil termometresi ile 9 kbar basınçta $639-662{ }^{\circ} \mathrm{C}$ (ortalama 646 $\left.{ }^{\circ} \mathrm{C}\right)$ arasında değişen sıcaklıklar vermiştir. 
Klasik yöntemlerle hesaplanan basınç değeri bu termometrede sıcaklık hesabında kullanılmıştır. Rutil termometresiyle TitaniQ termometresi birleştirildiğinde ofiyolitik meta-gabroların basınç-sıcaklık koşulları hesaplanmıştır. Kuvarsın $\mathrm{Ti}$ içeriğginin eş değer eğrileri ile rutilin $\mathrm{Zr}$ içeriğinin eş değer eğrileri çakıştırıldığında elde edilen maksimum basınç-sıcaklık koşulları 10 kbar ve $660{ }^{\circ} \mathrm{C}$ olarak belirlenmiştir. TitaniQ termometresi kuvars ve rutil içeren orta-yüksek dereceli metamorfik kayaların basınç-sıcaklık koşullarının saptanabilmesi için güvenilir ve ideal bir termobarometredir. Meta-ofiyolitik kayaların basınç-sıcaklık koşulları bu kayaların Kazdağ Masifi içerisinde daha yüksek basınçlı ayrı bir tektonik dilim olduğunu ve yaklaşık $35 \mathrm{~km}$ de amfibolit fasiyesinde metamorfizma geçirdiğini ifade etmektedir. Metamorfizma Neo-Tetis okyanusuna ait İzmir-Ankara kolunun kuzeye doğru Sakarya Zonu altına dalması nedeniyle meydana gelmiştir. Bu da K-G yönlü bir sıkışmaya ve Kazdağ Masifi’nin içyapısının birbiri üzerine bindirmesine neden olmuştur. Birbiri üzerine bindirme muhtemelen Kazdağ Masifi'nin yüzeylemesi ve kalınlaşmasının ana nedeni olmaktadır.

\section{KATKI BELİRTME}

$\mathrm{Bu}$ çalışma 114Y834 nolu TÜBİTAK projesi ve Çanakkale Onsekiz Mart Üniversitesi Bilimsel Araştırma Projeleri Komisyonu Başkanlığı tarafindan FBA-2014-67 nolu proje ile desteklenmiştir. LA-ICPMS analizleri ve bu analizlerin yorumlanmasında yardımlarından dolayı Dr. Thomas Zack'a teşekkür ederim.

\section{EXTENDED SUMMARY}

In northwest Turkey, The Kazdağ Massif lies in the Sakarya Zone and is located in the south of the Biga
Peninsula. The Kazdăg Massif structurally forms a NE-SW - plunging anticlinorium of medium to high-grade metamorphic rocks representing the deepest section of continental crust exposed in northwest Turkey (Schuiling 1959; Bingöl 1969; Okay et al. 1991; Okay and Satır 2000; Duru et al. 2004). The medium-grade metamorphic basement rocks of the Kazdăg Massif are mainly composed of felsic gneisses, amphibolite, marble and meta-ophiolitic rocks at the basal - middle part of the massif, and metagranite associated migmatite, amphibolite, and marble intercalations at the top (e.g. Okay et al. 1991; Duru et al. 2004; Erdoğan et al. 2013; Yiğitbaş et al. 2014). The meta-ophiolitic rocks of the Kazdă̆ Massif occur in the core of the anticlinorium enveloped by a marble-rich sequence, which passes up to felsic gneisses with migmatite, marble and amphibolite (Bingöl 1969; Picket and Robertson 1996; Okay and Satır 2000; Duru et al. 2004; Erdoğan et al. 2013). The meta-ophiolitic rocks, a typical oceanic assemblage, consist of meta-ultramafic rocks and dark-green coloured, banded metagabbro. The meta-ultramafic rocks are dominated by massive meta-pyroxenite and meta-dunite that is partly serpentinized. The meta-gabbros are generally foliated and their primary texture is widely preserved. This unit is tectonically overlain by a marble-gneiss sequence (Duru et al. 2004; Yiğitbaş et al. 2014).

Trace element composition of rutile and quartz was determined for meta-gabbros from the meta-ophiolitic rocks in the Kazda $\breve{g}$ Massif by LA-ICP-MS. Rutile ( $\left.\mathrm{TiO}_{2}\right)$ is an important accessory mineral in a variety of magmatic and metamorphic rocks and commonly found in medium to high-grade metamorphic rocks from oceanic and continental subduction zones. Rutile is also a major titanium-bearing phase that carries the high field strength elements (HFSE's) 
and dominates the Nb, Ta and Ti budgets of many rocks in subduction zone systems. Rutile occurs as three different textural types in the studied samples. The most frequent type in samples (1184, 1202) is matrix rutile with a grain size between 80 and $90 \mu \mathrm{m}$. Rutile occurs as an inclusion in garnet (grain size of rutile: $20-40 \mu \mathrm{m}$ ) and in clinopyroxene (grain size of rutile: $10-20 \mu \mathrm{m}$. Moreover, larger crystals separated from metagabbros $(1130,1301)$ with a grain size between 100 - $300 \mu \mathrm{m}$ form intergrowths with ilmenite. The $\mathrm{Zr}$ contents of both matrix rutiles and rutile inclusions in garnet range from 176 to 428 ppm (average $335 \mathrm{ppm}$ ). The $\mathrm{Hf}$ contents range between 8 and 18. The $\mathrm{Nb}$ and Ta concentrations vary from 120 to 811 and from 7 to 73 , respectively. The propagation in concentrations and element ratios changes from sample to sample, which is more pronounced for $\mathrm{Nb}$ and $\mathrm{Ta}$ elements than $\mathrm{Zr}$ and $\mathrm{Hf}$ elements. $\mathrm{Nb}$ and Ta exhibit a strong positive correlation (Figure 6a). $\mathrm{Zr}$ and Hf also indicate a positive correlation, but less distinct (Figure 6b). On the other hand, Ta and Zr show a poor correlation (1184), although three samples (1202, $1130,1301)$ indicated a positive correlation (Figure 6c).

$\mathrm{Nb} / \mathrm{Ta}$ ratios for rutile rims and cores are different from one another in one sample. The cores of rutile grains from sample 1130 are generally characterized by low $\mathrm{Nb} /$ Ta ratios of $17-$ 18 whereas the rims exhibit relatively high $\mathrm{Nb} / \mathrm{Ta}$ ratios of 19-23. The enrichment of $\mathrm{Nb}$ and Ta with slightly high $\mathrm{Nb} / \mathrm{Ta}$ ratios in the rims of rutile may result from breakdown of hydrous minerals such as biotite (Stepanov and Hermann, 2013).

$\mathrm{Nb} / \mathrm{Ta}$ and $\mathrm{Zr} / \mathrm{Hf}$ show positive correlation, which is probably produced by silicate fractionation (Münker et al. 2003; Weyer et al. 2003; Schmidt et al. 2009). Subchondritic $\mathrm{Nb} / \mathrm{Ta}$ ratios occur in rutile from both medium to high-grade metamorphic regions (e.g. Meyer et al. 2011; Luvizotto and Zack 2009; Ewing et al. 2013) and HP metamorphic regions (Xiao et al. 2006; John et al. 2011; Huang et al. 2012). Rutile compositions mostly display subchondritic $\mathrm{Nb} / \mathrm{Ta}$ values (chondritic value 19.9, Münker et al. 2003) with a range of 11-19 and $\mathrm{Zr} / \mathrm{Hf}$ values (chondritic value $34.3 \pm 0.3$, Münker et al. 2003) range between 20 and 33 (Fig. 7c). However, two rutile grains from sample 1301 and sample 1130 have suprachondritic $\mathrm{Nb} / \mathrm{Ta}$ and $\mathrm{Zr} / \mathrm{H} f$ values. $\mathrm{Nb} /$ $\mathrm{Ta}$ and $\mathrm{Zr} / \mathrm{Hf}$ ratios increase with a decrease in $\mathrm{Ta}$ and Hf contents (Figure 7a, b). Accordingly, the increase in $\mathrm{Nb} / \mathrm{Ta}$ ratios with the decreased $\mathrm{Ta}$ content can be linked to the effect of metamorphic dehydration at subduction zones on rutile $\mathrm{Nb} / \mathrm{Ta}$ differentiation (Schmidt et al. 2009; Gao et al. 2014). Dehydration metamorphism is a common mechanism for rutile formation in subduction processes. Nb and Ta have the same oxidation state and similar ionic radii (Meinhold, 2010) and thus would remain tightly coupled during geochemical processes in the crust-mantle differentiation system. However, there is a significant difference in their mass, which may be a potential cause for $\mathrm{Nb} / \mathrm{Ta}$ differentiation during geochemical processes.

The widespread occurrence of quartz in igneous, metamorphic, hydrothermal and sedimentary rocks attests to its stability over a wide range of $P-T$ conditions. The pressure dependence of the TitaniQ thermometer makes it potentially perfect barometer for ophiolitic metagabbros. The ophiolitic meta-gabbros contain rutile and quartz, thus $P$-T dependencies of Ti-inquartz can be combined with P-T dependencies of $Z r$-in-rutile to estimate pressure and temperature of crystallization. Ti contents of quartz are ranging between 28 and 42 ppm (average $36 \mathrm{ppm}$ ). A $P-T$ diagram of ofiyolitik meta-gabbro samples 
with the range of Ti-in-quartz and Zr-in-rutile values plotted as isopleths. A P-T estimate can be obtained from the intersection of the Ti-in-quartz isopleths with the Zr-in-rutile isopleths, which yielded metamorphism conditions of $\sim 660{ }^{\circ} \mathrm{C}$ and $10 \mathrm{kbar}$ (Figure 8). TitaniQ thermobarometer is a trustworthy thermobarometry for medium to high-grade metamorphic rocks, which gives more reliable pressure and temperature. The $P-T$ conditions of meta-ophiolitic rocks suggest that they occur as a different separate higherpressure tectonic slice in the Kazdă metamorphic sequence. Amphibolite-facies metamorphism resulted from northward subduction of the IzmirAnkara branch of the Neo-Tethyan Ocean under the Sakarya Zone. Metamorphism was followed by internal imbrication of the Kazdăg metamorphic sequence resulting from southerly directed compression during the collision.

\section{DEĞINILEN BELGELER}

Austrheim, H., Putnis, C.V., Engvik, A.K. ve Putnis, A., 2008. Zircon coronas around Fe-Ti oxides: a physical reference frame for metamorphic and metasomatic reactions. Contribution to Mineralogy and Petrology 156, 517-527.

Aysal, N., Ustaömer, T., Öngen, S., Keskin, M., Köksal, S., Peytcheva, I. ve Fanning, M., 2012. Origin of the Early-Middle Devonian Magmatism in the Sakarya Zone, Nw Turkey: Geochronology, Geochemistry and Isotope Systematics. Journal of Asian Earth Sciences 45, 201-222.

Baldwin, J.A. ve Brown, M., 2008. Age and duration of ultrahigh-temperature metamorphism in the Anápolis Itauçu Complex, Southern Brasília Belt, central Brazil - constraints from U-Pb geochronology, mineral rare earth element chemistry and trace element thermometry. Journal of Metamorphic Geology 26, 213-233.

Beccaletto, L. ve Jenny, C., 2004. Geology and Correlation of the Ezine Zone: A Rhodope Fragment in NW Turkey? Turkish Journal of Earth Sciences 13, 145-176.
Bingöl, E. 1969. Kazdağ Masifi'nin Merkezi ve GD Kesiminin Jeolojisi. MTA Dergisi 72, 110-123.

Brenan, J.M., Shaw, H.F., Phinney, D.L. ve Ryerson, F.J., 1994. Rutile-aqueous fluid partitioning of $\mathrm{Nb}$, $\mathrm{Ta}, \mathrm{Hf}, \mathrm{Zr}, \mathrm{U}$ and Th: implications for high field strength element depletions in island-arc basalts. Earth and Planetary Science Letters 128, 327-339.

Cavazza, W., Okay, A.I. ve Zattin, M., 2009. Rapid early-middle Exhumation of the Kazdağ Massif (western Anatolia). International Journal of Earth Sciences 98, 1935-1947.

Deer, W.A., Howie, R.A., Zussman, J., 1992. An Introduction to Rock-Forming Minerals. Longman Group, Harlow, UK.

Ding, X., Hu, Y.H., Zhang, H., Li, C.Y., Ling, M.X. ve Sun, W.D., 2013. Major $\mathrm{Nb} / \mathrm{Ta}$ fractionation recorded in garnet amphibolite facies metagabbro. Journal of Geology 121, 255-274.

Duru, M., Pehlivan, Ş., Şentürk, Y., Yavaş, F. ve Kar, H., 2004. New Results on the Lithostratigraphy of the Kazdağ Massif in Northwest Turkey. Turkish Journal of Earth Sciences 13, 177-186.

Dürr, S., Alther, R., Keller, J., Okrusch, M. ve Seidel, E., 1978. The median Aegean crystalline belt: Stratigraphy, structure, metamorphism, magmatism. In: Closs, H., Roeder, D., Schmidt, K., (eds) Alps, Appenines and Hellenides: Stuttgart, Scheweizerbart, pp. 455-476.

Eggins, S., Kinsley, L. ve Shelley, J., 1998. Deposition and element fractionation processes during atmospheric pressure laser sampling for analysis by ICP-MS. Applied Surface Science 127, 278 286.

Erdoğan, B., Akay, E., Hasözbek, A., Satır, M. ve Siebel, W., 2013. Stratigraphy and tectonic evolution of the Kazdağ Masif (NW Anatolia) based on field studies and radiometric ages. International Geology Review 55, 2060-2082.

Ewing, T.A.,, Herman, J. ve Rubatto, D., 2013. The robustness of the Zr-in-rutile and Ti-inzircon thermometers during high-temperature metamorphism (Ivrea-Verbano zone, northern Italy). Contribution to Mineralogy and Petrology 165, 757-779.

Ferry, J.M. ve Spear, F.S., 1978. Experimental calibration of the partitioning of $\mathrm{Fe}$ and $\mathrm{Mg}$ between biotite and garnet. Contribution to Mineralogy and Petrology 66, 113-117. 
Ferry, J.M. ve Watson, E.B., 2007. New thermodynamic models and revised calibrations for the Ti-inzircon and $\mathrm{Zr}$-in-rutile thermometers. Contribution to Mineralogy and Petrology 154, 429-437.

Foley, S., Tiepolo, M., Vannucci, R., 2002. Growth of early continental crust controlled by melting of amphibolite in subduction zones. Nature 417: 837-840.

Foley, S.F., Barth, M.G. ve Jenner, G.A., 2000. Rutile/ melt partition coefficients for trace elements and assessment of the influence of rutile on the trace element characteristics of subduction zone magmas. Geochimica Cosmochimca Acta 64, 933-938.

Gao, X.Y., Zheng, F.Y., Xia, X.P. ve Chen, Y.P., 2014. $\mathrm{U}-\mathrm{Pb}$ ages and trace element of metamorphic rutile from ultrahigh-pressure quartzite in the Sulu orogen. Geochimica Cosmochimica Acta 143, 87114.

Graham, J. ve Morris, R.C., 1973. Tungsten- and antimony substituted rutile. Mineralogical Magazine 39, 470-473.

Green, T.H., 1995. Significance of $\mathrm{Nb} / \mathrm{Ta}$ as an indicator of geochemical processes in the crust-mantle system. Chemical Geology 120, 347-359.

Hermann, J., Spandler, C., Hack, A. ve Korsakov, A., 2006. Aqueous fluids and hydrous melts in high-pressure and ultra-high pressure rocks: implications for element transfer in subduction zones. Lithos 92, 399-417.

Horng, W.S. ve Hess, P.C., 2000. Partition coefficients of $\mathrm{Nb}$ and $\mathrm{Ta}$ between rutile and anhydrous haplogranite melts. Contribution to Mineralogy and Petrology 138, 176-185.

Huang, J., Xiao. Y.L., Gao, Y.J., Hou, Z.H. ve Wu, W., $2012 \mathrm{Nb}-\mathrm{Ta}$ fractionation induced by fluid-rock interaction in subduction-zones: constraints from UHP eclogite- and vein-hosted rutile from the Dabie orogen, Central-Eastern China. Journal of Metamorphic Geology 30, 821-842.

Jochum, K.P. ve Nehring, F., 2006. NIST 610: GeoReM preferred values (11/2006). GeoReM http:// georem.mpch-mainz.gwdg.de.

John, T., Scherer, E.E., Haase, K. ve Schenk, V., 2004. Trace element fractionation during fluid-induced eclogitization in a subducting slab: trace element and Lu-Hf-Sm-Nd isotope systematics. Earth and Planetary Science Letters 227, 441-456.
John, T., Klemd, R., Klemme, S., Pfander, J., Hoffmann, J. ve Gao, J., 2011. Nb-Ta fractionation by partial melting at the titanite-rutile transition. Contribution to Mineralogy and Petrology 161, 35-45.

Klemme, S., Prowatke, S., Hametner, K., Gunther, D., 2005. Partitioning of trace elements between rutile and silicate melts: Implications for subduction zones. Geochimica Cosmochimica Acta 69, 23612371.

Kohn, M.J.ve Spear, F.S., 1990. Two new geobarometers for garnet amphiboliteso with applications to southeastern Vermont. American Mineralogist 75, 89-96.

Luvizotto, G.L. ve Zack, T., 2009. Nb and Zr behavior in rutile during high-grade metamorphismand retrogression:An example fromthe Ivrea-Verbano Zone. Chemical Geology 261, 303-317.

Luvizotto, G.L., Zack, T., Meyer, H.P., Ludwig, T., Triebold, S., Kronz, A., Munker, C., Stockli, D.F., Prowatke, S., Klemme, S., Jacob, D.E. ve Eynatten, H., 2009. Rutile crystals as potential trace element and isotope mineral standards for microanalysis. Chemical Geology 261, 346-369.

Meinhold, G., 2010. Rutile and its applications in earth sciences. Earth Science Review 102, 1-28.

Meinhold, G., Kostopoulos, D., Frei, D.,, Himmerkus, F. ve Reischmann, T., 2010. U-Pb LA-SF-ICP-MS zircon geochronology of the Serbo-Macedonian Massif, Greece: Palaeotectonic constraints for Gondwana-derived terranes in the Eastern Mediterranean. International Journal of Earth Sciences 99, 813-832.

Meyer, M., John, T., Brandt, S. ve Klemd, R., 2011. Trace element composition of rutile and the application of Zr-in-rutile thermometry to UHT metamorphism (Epupa Complex, NW Namibia). Lithos 126, 388-401.

Miller, C., Zanetti, A. ve Thoni, M., 2007. Eclogitisation of gabbroic rocks: Redistribution of trace elements and $\mathrm{Zr}$ in rutile thermometry in an EoAlpine subduction zone (Eastern Alps). Chemical Geology 239, 96-123.

Moix, P., Beccaletto, L., Kozur, H., Hochard, C., Rosselet, F. ve Stampfli, G.M., 2008. A new classification of the Turkish terranes and sutures and its implication for the paleotectonic history of the region. Tectonophysics 451, 7-39. 
Münker, C., Pfänder, J.A., Weyer, S., Büchl, A., Kleine, T. ve Mezger, K., 2003. Evolution of planetary cores and the Earth-Moon system from $\mathrm{Nb} / \mathrm{Ta}$ systematic. Science 301, 84-87.

MTA, 2012. General and economic geology of the Biga Peninsula. Special Publication Series, 28, p 326 (in Turkish).

Okay, A.I., 1984. Distribution and characteristics of the northwest Turkish blueschists. In: Robertson, A.H.F., Dixon, J.E., (eds) The geological evolution of the eastern Mediterranean. Geological Society of Special Publication No:17, 455-466.

Okay, A.I., 1986. High-pressure/low-temperature metamorphic rocks of Turkey: Geological Society of America Memoir 164, 333-347.

Okay, A.I. ve Tüysüz, O., 1999. Tethyan sutures of northern Turkey. In: Durand B, Jolivet L, Horváth F, Séranne M (eds) The Mediterranean Basins: Tertiary Extension within the Alpine Orogen. Geological Society Special Publications No: 156, 475-515.

Okay, A.I. ve Satır, M., 2000. Coeval plutonism ve metamorphism in a latest Oligocene metamorphic core complex in Northwest Turkey. Geological Magazine 137, 495-516.

Okay, A.I. ve Göncüoğlu, M.C., 2004. The Karakaya Complex: A Review of Data and Concepts. Turkish Journal of Earth Sciences 13, 77-95.

Okay, A.I., Satır, M. ve Siebel, W., 2006. Pre-Alpide and Mesozoic orogenic events in the Eastern Mediterranean region. Geological Society of Special Publication No:32, 389-405

Okay, A.I., Satır, M., Maluski, H., Siyako, M., Monie, P., Metzger, R. ve Akyüz, S., 1996. Paleo-and Neotethyan events in northwest Turkey. In: Yin, A., Harrison, M., (eds) Tectonics of Asia. Cambridge University Press, Cambridge, pp. 420-441.

Philpotts, A.R., 1990. Principles of igneous and metamorphic petrology. Prentice Hall, Englewood Cliffs.

Pickett, E.A., Robertson, A.H.F. ve Dixon, J.E., 1996. The Karakaya Complex, NW Turkey: A Palaeo Tethyan Accretionary Complex, Geology of the Black Sea Region. Geological Society of Special Publication No: 153, 995-1009.

Rudnick, R.L., Barth, M., Horn, I. ve McDonough, W.F., 2000. Rutile-bearing refractory eclogites: missing link between continents and depleted mantle. Science 287, 278-281.

Scambelluri, M., Bottazzi, P., Trommsdorff, V., Vannucci, R., Hermann, J., Gomez-Pugnaire, M.T. ve Lopez-Sanchez-Vizcaino, V., 2001. Incompatible element-rich fluids released by antigorite breakdown in deeply subducted mantle. Earth and Planetary Science Letters 192, 457-470.

Schmidt, M.W., Dardon, A., Chazot, G. ve Vannucci, R., 2004. The dependence of $\mathrm{Nb}$ and Ta rutilemelt partitioning on melt composition and $\mathrm{Nb} / \mathrm{Ta}$ fractionation during subduction processes. Earth and Planetary Science Letters 226, 415-432.

Schmidt, A., Weyer, S., Mezger, K., Scherer, E.E., Xiao, Y.L., Hoefs, J. ve Brey, G.P., 2008. Rapid eclogitisation of the Dabie-Sulu UHP terrane: constraints from Lu-Hf garnet geochronology. Earth and Planetary Science Letters 273, 203-213.

Schmidt A, Weyer S, John T, Brey GP (2009) HFSE systematics of rutile-bearing eclogites: new insights into subduction zone processes and implications for the earth's HFSE budget. Geochim Cosmochim Acta 73: 455-468

Spear, F.S., 1993. Metamorphic phase equilibria and pressure-temperature-time paths. Mineralogical Society of America Washington.

Spear, F.S., Wark, D.A. ve Cheney, J.T., 2006. Zr-inrutile thermometry in blueschists from Sifnos, Greece. Contribution to Mineralogy and Petrology 152, 375-385.

Stalder, R., Foley, S.F., Brey, G.P. ve Horn, I., 1998. Mineral-aqueous fluid partitioning of trace elements at 900-1200 $\mathrm{C}$ and 3.0-5.7 GPa: new experimental data for garnet, clinopyroxene, and rutile, and implications for mantle metasomatism. Geochimica Cosmochimica Acta 62, 1781-1801.

Stepanov, A.S. ve Hermann, J., 2013. Fractionation of $\mathrm{Nb}$ and Ta by biotite and phengite: implications for the "missing Nb paradox". Geology 41, 303-306.

Şengör, A.M.C. ve Yilmaz, Y., 1981. Tethyan evolution of Turkey: a plate tectonic approach. Tectonophysics 75, 181-241.

Şengün, F. ve Zack, T., 2016. Trace element composition of rutile and Zr-in-rutile thermometry in metaophiolitic rocks from the Kazdağ Massif, NW Turkey. Mineralogy and Petrology, DOI 10.1007/ s00710-016-0433-7. 
Şengün, F., Yigitbas, E. ve Tunç, İ.O., 2011. Geology and Tectonic Emplacement of Eclogite and Blueschist, Biga Peninsula, Northwest Turkey. Turkish Journal of Earth Sciences 20, 273-285.

Tatsumi, Y. ve Nakamura, N., 1986. Composition of aqueous fluid from serpentine in the subducted lithosphere. Geochemical Journal 20, 191-196.

Tetiker, S., Yalçın, H., Bozkaya, Ö. ve Göncüoğlu, M. C., 2015. Diagenetic to Low-Grade Metamorphic Evolution of the Karakaya Complex in northern Turkey based on phyllosilicate mineralogy. Mineralogy and Petrology, 109, 201-215.

Thomas, J.B., Watson, E.B., Spear, F.S. ve Wark, D.A., 2015. TitaniQ recrystallized: experimental confirmation of the original Tiinquartz calibrations. Contribution to Mineralogy and Petrology 169, 27.

Thomas, J.B., Watson, E.B., Spear, F.S., Shemella, F.S., Nayak, S.K. ve Lanzirotti, A., 2010. TitaniQ under pressure: the effect of pressure and temperature on the solubility of Ti in quartz. Contribution to Mineralogy and Petrology 160, 743-759.

Tomkins, H.S., Powell, R. ve Ellis, D.J., 2007. The pressure dependence of the zirconium-in-rutile thermometer. Journal of Metamorphic Geology 25, 703-713.

Wark, D.A. ve Watson, E.B., 2006. The TitaniQ: a Titanium-in-quartz geothermometer. Contribution to Mineralogy and Petrology 152, 743-754.

Watson, E.B,, Wark, D.A. ve Thomas, J.B., 2006. Crystallization thermometers for zircon and rutile. Contribution to Mineralogy and Petrology 151, 413-433.

Weyer, S., Muenker, C. ve Mezger, K., 2003. Nb/Ta, Zr/ $\mathrm{Hf}$ and REE in the depleted mantle: implications for the differentiation history of the crust-mantle system. Earth and Planetary Science Letters 205, 309-324.

Wilson, S.A., 1997. The collection, preparation, and testing of USGS reference material BCR-2, Columbia River, Basalt: U.S. Geological Survey Open-File Report 98.

Xia, Q.X., Zheng, Y.F. ve Hu, Z.C., 2010. Trace elements in zircon and coexisting minerals from low-T/UHP metagranite in the Dabie orogen: implications for action of supercritical fluid during continental subduction-zone metamorphism. Lithos 114, 385-412.
Xiao, Y.L., Sun, W.D., Hoefs, J., Simon, K., Zhang, Z.M,. Li, S,G, ve Hofmann, A.W., 2006. Making continental crust through slab melting: constraints from niobium-tantalum fractionation in UHP metamorphic rutile. Geochimica Cosmochimica Acta 70, 4770-4782.

Xiong, X.L., Adam, J. ve Green, T.H., 2005. Rutile stability and rutile/melt HFSE partitioning during partial melting of hydrous basalt: implications for TTG genesis. Chemical Geology 218, 339-359.

Van Achterbergh, E., Ryan, C.G. ve Griffin, W.L., 2000. GLITTER (Version 3.0, On-line Interactive Data Reduction for LA-ICPMS). Maquarie Research Ltd.

Yiğitbaş, E., Şengün, F. ve Tunç, İ.O., 2014. PreNeogene tectonic units in the Biga Peninsula and an approach to geodynamic evolution of region. TUBITAK project (110Y281).

Zack, T., Kronz, A., Foley, S.F. ve Rivers, T., 2002. Trace element abundances in rutiles from eclogites and associated garnet mica schists. Chemical Geology 184, 97-122.

Zack, T., Moraes, R. ve Kronz, A., 2004. Temperature dependence of $\mathrm{Zr}$ in rutile: empirical calibration of a rutile thermometer. Contribution to Mineralogy and Petrology 148, 471-488.

Zhang, J.X., Yu, S., Meng, F.C. ve Li, J.P., 2009. Paired high-pressure granulite and eclogite in collision orogens and their geodynamic implications. Acta Petrologica Sinica 25: 2050-2066 (in Chinese with English abstract).

Zheng, Y.F., Xia, Q.X., Chen, R.X. ve Gao, X.Y., 2011. Partial melting, fluid supercriticality and element mobility in ultrahigh-pressure metamorphic rocks during continental collision. Earth Science Reviews 107, 342-374.

\begin{tabular}{ll}
\hline $\begin{array}{l}\text { Makale Geliş Tarihi } \\
\text { Kabul Tarihi }\end{array}$ & $: 23$ Şubat 2016 \\
& $: 21$ Mart 2016 \\
Received & $: 23$ February 2016 \\
Accepted & $:$ 21 March 2016
\end{tabular}

